\title{
Comparative hydrology across AmeriFlux sites: The variable roles of climate, vegetation, and groundwater
}

\author{
S. E. Thompson, ${ }^{1}$ C. J. Harman, ${ }^{2}$ A. G. Konings, ${ }^{1}$ M. Sivapalan, ${ }^{2,3,4}$ A. Neal, ${ }^{5}$ \\ and P. A. Troch ${ }^{5}$ \\ Received 26 July 2010; revised 26 April 2011; accepted 5 May 2011; published 15 July 2011.
}

[1] Watersheds can be characterized as complex space-time filters that transform incoming fluxes of energy, water, and nutrients into variable output signals. The behavior of these filters is driven by climate, geomorphology, and ecology and, accordingly, varies from site to site. We investigated this variation by exploring the behavior of evapotranspiration signals from 14 different AmeriFlux sites. Evapotranspiration is driven by water and energetic forcing and is mediated by ecology and internal redistribution of water and energy. As such, it integrates biological and physical controls, making it an ideal signature to target when investigating watershed filtering. We adopted a paradigmatic approach (referred to as the null model) that couples the Penman-Monteith equation to a soil moisture model and explored the deviations between the predictions of the null model and the observed AmeriFlux data across the sites in order to identify the controls on these deviations and their commonalities and differences across the sites. The null model reproduced evapotranspiration fluxes reasonably well for arid, shallow-rooted systems but overestimated the effects of water limitation and could not reproduce seasonal variation in evapotranspiration at other sites. Accounting for plant access to groundwater (or deep soil moisture) reserves and for the effects of soil temperature on limiting evapotranspiration resolved these discrepancies and greatly improved prediction of evapotranspiration at multiple time scales. The results indicate that site-specific hydrology and climatic factors pose important controls on biosphere-hydrosphere interactions and suggest that plant-water table interactions and early season phenological controls need to be incorporated into even simple models to reproduce the seasonality in evapotranspiration.

Citation: Thompson, S. E., C. J. Harman, A. G. Konings, M. Sivapalan, A. Neal, and P. A. Troch (2011), Comparative hydrology across AmeriFlux sites: The variable roles of climate, vegetation, and groundwater, Water Resour. Res., 47, W00J07, doi:10.1029/2010WR009797.

\section{Introduction: Catchment Evapotranspiration Response in Space and Time}

[2] The dynamics of evapotranspiration (ET) are fundamentally linked to catchment water balance and thus the hydrological responses of watersheds when subject to incoming rainfall. Predicting ET and its response to changing climate or land uses remains an important theoretical challenge. Challenges in ET prediction arise in part from the wide array of process interactions involved in ET dynamics and the propagation of information across the time scales associated with these processes [Siqueira et al., 2006;

\footnotetext{
${ }^{1}$ Nicholas School of the Environment, Duke University, Durham, North Carolina, USA.

${ }^{2}$ Department of Civil and Environmental Engineering, University of Illinois at Urbana-Champaign, Urbana, Illinois, USA.

${ }^{3}$ Department of Geography, University of Illinois at UrbanaChampaign, Urbana, Illinois, USA.

${ }^{4}$ Department of Water Management, Delft University of Technology, Delft, Netherlands.

${ }^{5}$ Department of Hydrology and Water Resources, University of Arizona, Tucson, Arizona, USA.
}

Copyright 2011 by the American Geophysical Union. 0043-1397/11/2010WR009797
Mahecha et al., 2010]. For instance, stomatal dynamics and plant physiological controls vary on rapid (minutes to hourly) time scales; diurnal cycles impose a strong daily signal on ET; the buildup of water stress during periods of drought affects ET over days to weeks; seasonal variations in energy and water availability drive longer period fluctuations, and changes in climatic forcing and vegetation structure impinge on interannual variability. Because ET integrates water and energy fluxes, and biological and physical controls on landscape filtering [Siqueira et al., 2006], it is an attractive signature to examine theoretically, but interpreting results requires unpicking the roles of both biological and physical processes and their interdependencies. One approach toward this problem is to examine data and signatures of watershed response across multiple sites, identifying commonalities and differences across diverse locations. Using such a comparative approach Troch et al. [2009] showed that if the annual catchment water balance were expressed as the Horton index, a ratio between evapotranspiration and the plant-available water (i.e., throughfall minus rapid runoff), then the Horton index at a site was remarkably invariant between years, and varied between sites as a function of mean aridity. These trends are suggestive of a simplifying principle that constrains water 

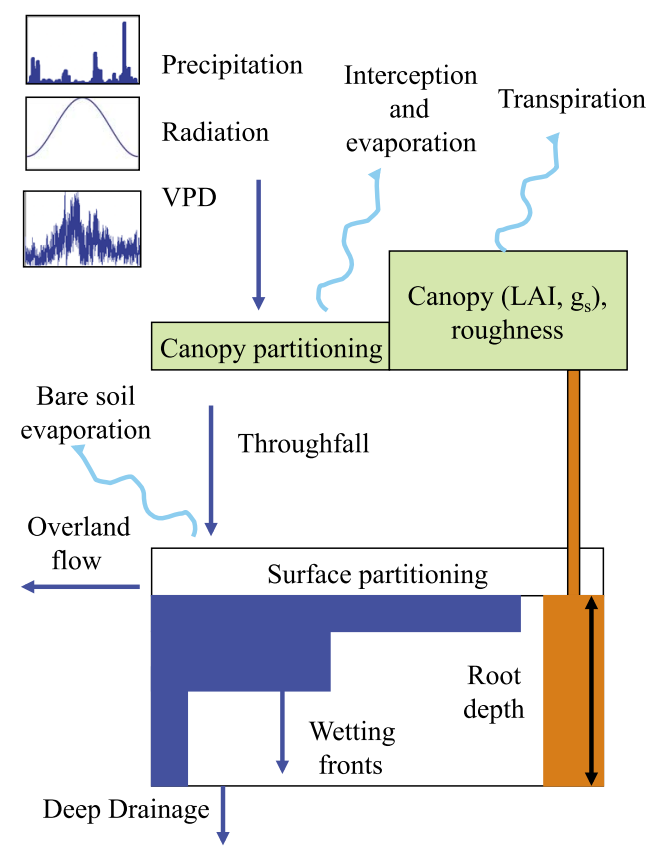

Figure 1. Schematic representation of the multiple wetting front model (MWF) coupled with canopy interception and transpiration.

balance at certain spatial and temporal scales. The invariance observed by Troch et al. [2009] suggests that withincatchment processes buffer the water balance partitioning from year to year. The nature of these processes is yet to be conclusively demonstrated, but the plasticity of ecosystem water use between years is an attractive candidate [Troch et al., 2009].

[3] This study aims to contribute toward investigation of hydrological partitioning by exploring the controls on within-year ET variation at patch scales, and how these vary between sites. To do this we examine site-to-site variation in ET at seasonal to annual time scales using detailed sitespecific data available from eddy covariance measurements made at 14 AmeriFlux sites. The data are interrogated with a coupled water and energy balance model, parameterized with site-specific data in an effort to learn about the process controls on ET under different climatic, soil and vegetation regimes. Similar approaches have been used in evaluations of land surface models [Stöckli and Vidale, 2005; Mahecha et al., 2010; Blyth et al., 2010; Fisher et al., 2005, 2008; Falge et al., 2005]. In this study the model is used in a topdown modeling framework [Sivapalan et al., 2003; Klemeš, 1983 ] in which the model encodes hypotheses that are tested by confronting their quantitative predictions with data. Where the model fails to account for observations at a site, and this failure cannot be readily explained by the model parameterization, the process representation is modified to resolve discrepancies between prediction and observation. The model thus becomes a tool to learn about data, to explore variability between sites and to explain the patterns of difference and commonality observed in the data records. Top down modeling has been applied in other hydrological problems, for instance to determine the dominant controls (climatic, edaphic) and scales of control (annual, seasonal, or event scale) on streamflow in contrasting catchments [Sivapalan et al., 2003; Jothityangkoon and Sivapalan,
2009], and to assess the predictability of hydrological response in managed midwestern U.S. watersheds [Basu et al., 2010]. By systematically comparing model predictions of ET fluxes to data, updating the model and repeating the comparison, we aim to elucidate a structure of process controls on ET and their variation between sites. The goal of this study is not to develop a new model for ET prediction. Although the null model is updated throughout the study, these modifications are diagnostic in nature and the development of improved models is left for future research.

\section{Methods}

[4] Some results are briefly discussed in this section in order to motivate the modifications that were made to the model. Otherwise we have attempted to separate discussion of methods and results.

\subsection{The Null Model}

[5] Fundamentally, energy and mass must be conserved in any control volume that encompasses the land surface. Climatic and atmospheric drivers of surface energy and water balance therefore constitute the primary controls on ET. The partitioning of energy and water to ET fluxes within a control volume is also driven by the efficiency of transfer processes for energy and water. Therefore many site specific factors such as the hydraulic resistance of soil and plant vessels [Green et al., 2006; Whalley et al., 2005; Hamza et al., 2001; Yang and Tyree, 1993, 1994; Comstock and Sperry, 2000]; stomatal and canopy resistance [Linacre, 1993; Wallace, 1995; Dickinson et al., 1991; Raupach et al., 1996; Raupach and Thom, 1981]; additional energy sinks [Betts et al., 1996; Blyth et al., 2010]; and the degree of plant access to available water via their root network drive partitioning to ET [Jackson et al., 1996; Schenk and Jackson, 2002; Feddes et al., 2001]. The classical paradigm for predicting ET can be expressed as

$$
\mathrm{ET}=f_{1}(h \nu, \mathrm{VPD}, T) f_{2}(\text { land surface }) f_{3}(\theta),
$$

where $f_{1}$ is a function of available energy $(h \nu)$ and atmospheric demand (determined by vapor pressure deficit (VPD) and temperature $T), f_{2}$ is a function of land surface properties describing resistance to water vapor transfer from the land surface to the atmosphere, and $f_{3}$ is a function of soil moisture $(\theta)$ which accounts for water availability. Conventionally the product of $f_{1}$ and $f_{2}$ is combined into a single term known as the potential evaporation EP. Equation (1) is the basis for the null model for ET. Although simple in comparison to existing state-of-the-art ET models in the land-atmosphere interaction community (e.g., the LPJ model [Sitch et al., 2003], Biome-BGC [White et al., 2000], SVAT-CN [Caldwell et al., 1986], HIRVAC [Goldberg and Bernhofer, 2001], and CANVEG [Lai et al., 2000]), it is a widely used predictive approach in catchment hydrology and forms the basis for ET predictions in a number of modeling platforms, e.g., SWAT, HSM [Neitsch et al., 2005; Yu and Schwartz, 1998; Yu et al., 2000] and thus impacts the predictions of hydrological models [Wang et al., 2006].

[6] The null model was implemented by coupling the multiple wetting front model (MWF) [Struthers et al., 2006], used to assess water availability, to the PenmanMonteith equation, used to assess potential evaporation. The 
model layout is shown schematically in Figure 1. The MWF model is a kinematic wave approximation to Richards equation and has previously been validated against the full solution to Richards equation as well as lysimeter data [Struthers et al., 2006]. The MWF model reproduced temporal patterns of soil moisture availability well when compared with measured data at some of the AmeriFlux sites considered in this study, yielding an RMS error of approximately $2.5 \%$ water content. We note, however, that in general AmeriFlux soil moisture data is confined to the surface soils, so this validation does not span the entire soil column. Potential evaporation was computed using the Penman-Monteith equation, given by

$$
\mathrm{EP}=\frac{\Delta\left(R_{n}-G\right)+\rho_{a} c_{p} \frac{\mathrm{VPD}}{r_{a}}}{\Delta+\gamma\left(1+\frac{r_{s}}{r_{a}}\right)}
$$

where VPD is the vapor pressure deficit $(\mathrm{kPa}), \rho_{a}$ the mean air density at constant pressure $\left(\mathrm{kg} / \mathrm{m}^{3}\right), c_{p}$ is the specific heat of the air at constant pressure $\left(\mathrm{MJ} / \mathrm{kg} /{ }^{\circ} \mathrm{C}\right), \Delta$ is the slope of the saturation vapor pressure temperature relationship at air temperature $\left(\mathrm{kPa} /{ }^{\circ} \mathrm{C}\right), \gamma$ is the psychrometric constant $\left(\mathrm{kPa} /{ }^{\circ} \mathrm{C}\right)$, and $r_{s}$ and $r_{a}$ are the bulk surface and aerodynamic resistances $(\mathrm{S} / \mathrm{m})$. The aerodynamic resistance was calculated using the relationship

$$
r_{a}=\frac{\log \left(\frac{z_{m}-d}{z_{o m}}\right) \log \left(\frac{z_{h}-d}{z_{o h}}\right)}{k^{2} u_{z}}
$$

where $z_{m}$ and $z_{h}(\mathrm{~m})$ are the heights at which wind speed and relative humidity measurements were taken, respectively, $d$ is the zero plane displacement height $(\mathrm{m}), z_{o m}$ and $z_{o h}$ are the roughness length scales for momentum and heat and vapor $(\mathrm{m}), k$ is von Karman's constant (0.42) and $u_{z}$ is a reference wind speed at height $z_{m}(\mathrm{~m} / \mathrm{s})$ [Food and Agricultural Organization, 1998]. The surface resistance and roughness properties for the forested sites were related to the leaf area index ( $\mathrm{LAI} ; \mathrm{m}^{2} / \mathrm{m}^{2}$ ) and the stand density on the basis of the empirical approach of Nakai et al. [2008]. Following computation of the potential evaporation with the Penman-Monteith equation, the actual evapotranspiration was computed using an index of soil moisture availability. This index is set to 1 where the soil moisture exceeds the threshold for soil satiation $\theta^{*}(\%)$, or to zero if the soil moisture is less than the wilting point $\theta_{w}\left(\mathrm{~m}^{3} / \mathrm{m}^{3}\right)$, and scales linearly between $\theta_{w}$ and $\theta^{*}$ as

$$
\mathrm{ET}=\mathrm{EP}\left(\frac{\theta-\theta_{w}}{\theta^{*}-\theta_{w}}\right)
$$

In the absence of data regarding the root distribution and root water uptake strategies of the vegetation communities, the value of soil moisture $\theta$ used in equation (4) was the highest value within the specified root depth $r_{z}(\mathrm{~m})$. That is, we assumed that the plant root system was sufficiently plastic to supply evapotranspirative demand from water resources located anywhere in the rooting zone.

\subsection{Data}

[7] Data were taken from 14 AmeriFlux sites spanning the continental United States. The sites span a climatic gradient from arid (Kendall Grassland, Audubon Ranch and
Fort Peck) to mediterranean (Sky Oaks, Tonzi Ranch and Metolius Intermediate Pine), to warm and well watered (Austin Cary Forest, Donaldson Forest, Goodwin Creek and the Kennedy Space Center Oaks) to temperate sites with cold winters (Harvard Forest, Howland Forest Main and West Towers, and Morgan Monroe State Forest) [Drake et al., 2009; Dragoni et al., 2009; Hollinger et al., 2009; Hollinger, 2009; Law et al., 2009; Martin et al., 2009a, 2009b; Meyers, 2009a, 2009b, 2009c; Munger et al., 2009; Oechel, 2009; Scott, 2009; Baldocchi and Ma, 2011]. The sites also span a range of soil and vegetation types, with $\mathrm{C} 3$ and $\mathrm{C} 4$ grasses, shrublands, savannah ecosystems, evergreen and deciduous broadleaf forests represented. Metadata indicating the typical climate and vegetation conditions at each of the sites are provided in Table 1. AmeriFlux tower data (quality controlled at levels 3 and 4) were downloaded to provide time series of latent heat, radiation, precipitation, wind speed, air pressure, temperature, and vapor pressure deficit. Level 4 data were used preferentially: L4 data contain gap-filled and friction velocity $\left(u^{*}\right)$ filtered records, with quality flags indicating the caliber of gap filling. Some input variables were not available at the L4 level (specifically pressure and net radiation): these variables were obtained from the L3 data. Leaf area index data were obtained from ground-based measurements where available (namely, Morgan Monroe, Kennedy, Austin Cary, Donaldson, and Tonzi Ranch sites). Otherwise, LAI data were obtained from the Moderate Resolution Imaging Spectroradiometer (MODIS), using only the best quality (HQ1) data. These data are contaminated with gaps (representing $8 \%-44 \%$ of measurements). We thresholded the data to remove spurious minima and applied a smoothing spline (fifth-order Hermitian) to gap fill. The MODIS estimates were compared to point-scale LAI measurements where available. If there was a systematic bias between MODIS and the ground-based measurements we scaled the MODIS data so that the seasonality in LAI was preserved but the peak annual LAI was equal to that determined from ground-based measurements.

[8] Forcing data $\left(R_{n}, \mathrm{VPD}\right.$, and temperature $\left.T\right)$ at several sites contained large gaps ( $>10$ days) which were filled with representative values from the same day of the year at other time periods. Small gaps ( $<10$ days) were filled by linearly interpolating daily mean values using an 11-point fitting window. These values were then used to scale the average subdaily time series, generating an interpolated time series that preserved the typical pattern of diurnal variations.

[9] The model was parameterized on the basis of a literature review which considered literature relating to vegetation type, vegetation physiological parameters, soil data (soil series and texture), and any data regarding rainfall interception by the canopy at each site. For mixed forest stands, estimates of species specific properties (e.g., maximum stomatal conductance, $g_{s}$ ) were made by taking the weighted average of the property for each species in the stand, relative to the stand composition. In several sites where no literature values for soil depth or texture were available, USDA Soil Survey data were used to obtain local soil textural data and the mean depth to a confining layer, taken as representing the rooting depth. Textural parameters were used as input into a pedotransfer function [Saxton and Rawls, 2006] to obtain estimates of soil hydraulic properties (saturated hydraulic conductivity, Brooks-Corey parameters). The parameters used in the final model are presented in Table 2, 
while the data used to generate the model parameters and the relevant literature references are presented as auxiliary material. ${ }^{1}$

\subsection{Initial Model Evaluation}

[10] To robustly proceed with the top-down modeling approach, confidence is needed that mismatches between model and data can be attributed to missing processes rather than uncertainty in parameter values. A sensitivity analysis on the most uncertain model parameters, namely, the vegetation parameters (LAI and $g_{s}$ ) and the soil parameters (soil texture and depth) was therefore undertaken for all sites. Model results were obtained using the literature-based values of soil depth, LAI and $g_{s}$, and repeated as these parameters were increased and decreased by factors of 2 and 3. This variation was taken as a reasonable upper bound on the uncertainty in the measured parameters. The initial condition for soil moisture was not varied in this analysis, so increasing soil depth also increased the total volume of water initially stored. Sensitivity was determined by computing the proportional change in ET (i.e., $\mathrm{ET}_{\text {new }} / \mathrm{ET}_{\text {ref }}$ ) as a function of the proportional change in the parameter (e.g., $\left.\mathrm{LAI}_{\text {new }} / \mathrm{LAI}_{\text {ref }}\right)$. In the case of the soil texture, rather than factorially varying all soil parameters (hydraulic conductivity, porosity, satiation point, field capacity and wilting point), which neglects the typical covariation in these parameters, three standard soil types representing a sand, a loam and a clay were developed. The sensitivity of each site to the parameters was then explored in relation to broad site vegetation and climate characteristics in order to gain insight into the conditions under which uncertainty in soil and vegetation parameters would perturb model output.

[11] In addition to the sensitivity analysis the null model energy and water balances were scrutinized to determine whether discrepancies between modeled and measured ET could be explained by poor parameterization. Sites where the literature-based parameters did not allow the model to reproduce the peak ET value were investigated: large overestimates of peak ET were taken as an indicator that the EP estimate was too great at that site, while large underestimates of peak ET (if not explained by an underestimate in EP) were treated as indicating persistent water stress. On the basis of this investigation two parameter alterations were made: the first to the saturated hydraulic conductivity at Morgan Monroe State Forest and the second to the stomatal conductance at the Austin Cary State Forest (discussed further in section 3 ).

\subsection{Quantification of Model Error}

[12] Two measures of model performance were used, primarily on the basis of a comparison of the monthly ET signal between modeled and measured values. Error in the modeled time series was quantified as the root mean squared error (RMSE) (Table 3). The Akaike information criterion (AIC) was also computed for the model output as a way of assessing if additional process descriptions lead to meaningful improvements (see Table 4). Because the length of the time series of ET varied from site to site the AICs for

\footnotetext{
${ }^{1}$ Auxiliary materials are available in the HTML. doi:10.1029/ 2010WR009797.
} 
each site cannot be compared directly to each other. As the model was adapted, a reduction in both AIC and RMSE at the monthly time scale was taken as an indication of improved model performance. As a final indication of model performance across the range of time scales (half hourly to interannually) we also directly compared the Fourier power spectra of modeled and measured ET [cf. Siqueira et al., 2006; Mahecha et al., 2010].

\subsection{Modification 1: Interception}

[13] The first correction applied to the model was to add canopy interception. Canopy interception has a twofold impact on ET: it tends to increase ET immediately after storm events because of evaporation from the canopy itself, while decreasing ET over longer time scales by preventing water ingress to the root zone. The canopy storage model of Rutter et al. [1972, 1975], was used to account for interception. The Rutter model assumes a maximum interception volume (storage, $\mathrm{mm}$ ), which then evaporates, drains (and infiltrates) at a rate which declines exponentially from a maximum at the peak storage ( $A$ in Table 2 ) as described by shape parameter ( $B$ in Table 2). Parameters describing canopy interception were generally unavailable at species specific levels, and were estimated on the basis of functional type (e.g., grass versus needleleaf versus broadleaf), weighted by leaf area index. Where the addition of interception improved RMSE and decreased AIC, it was retained.

\subsection{Modification 2: Additional Water Sources}

[14] Following the interception correction $50 \%$ of the sites (Sky Oaks, Morgan Monroe, Kennedy, Metolius, Austin Cary, Donaldson and Tonzi Ranch) had discrepancies between model output and measurements that were consistent with water scarcity: either A) a reasonable fit between model and measurements during the early growing season, with a decline in late growing season ET appearing in the model but absent from measurements; or B) a failure of the model to adequately predict peak ET which could not be explained by an underestimate of EP or surface water losses (runoff or interception). Two hypotheses were proposed to explain the apparent appearance of water shortages in the model but not in the measurements:

[15] 1. Water that was lost to deep drainage in the model was available to plants in reality. This could occur through, e.g., vegetation accessing deep water stores in sand or fractured rock formations, through hydraulic redistribution, or through the presence of a low-permeability soil layer below the root zone that allowed a perched water table to form.

[16] 2. Plants access sources of water other than local rainfall, e.g., a regional groundwater aquifer, or water moving laterally through a perched water table.

[17] These hypotheses were investigated in several ways. Firstly, the bulk water balances for the sites $(P-$ ET) were computed. Secondly, the time series of ET and soil moisture, where measured, were inspected to determine whether clear evidence of plants accessing water from outside the vadose zone could be found. Next the model was used to evaluate the proportion of the water balance lost to deep drainage in the null case. Where this was significant the soil depth was increased (by factors of 2 and 3) to determine if increased soil storage (and therefore lower deep drainage 
Table 3. Root-Mean-Square Errors (RMSE) in the Model Output Relative to Measured ET Fluxes ${ }^{\mathrm{a}}$

\begin{tabular}{|c|c|c|c|c|c|c|c|c|c|c|c|}
\hline & \multirow{2}{*}{$\frac{\text { Base Model }}{\text { RMSE }}$} & \multicolumn{2}{|c|}{$\begin{array}{c}\text { Adding } \\
\text { Interception }\end{array}$} & \multicolumn{2}{|c|}{$\begin{array}{l}\text { Altering Soil } \\
\text { Depth }\end{array}$} & \multicolumn{2}{|c|}{$\begin{array}{c}\text { Adding } \\
\text { Groundwater }\end{array}$} & \multicolumn{2}{|c|}{ Energy Sink } & \multicolumn{2}{|c|}{$\begin{array}{c}\text { Growing Season } \\
\text { Index } \\
\end{array}$} \\
\hline & & RMSE & Change & RMSE & Change & RMSE & Change & RMSE & Change & RMSE & Change \\
\hline Sky Oaks & 123 & 106 & $-14 \%$ & 57 & $-46 \%$ & 54 & $-50 \%$ & & & & \\
\hline Morgan Monroe & 180 & 196 & $9 \%$ & 148 & $-18 \%$ & 118 & $-34 \%$ & 110 & $-39 \%$ & 105 & $-42 \%$ \\
\hline Harvard & 56 & 80 & $42 \%$ & & & & & & & & \\
\hline Kennedy & 119 & 156 & $31 \%$ & 80 & $-33 \%$ & 62 & $-48 \%$ & & & & \\
\hline Metolius & 174 & 187 & $7 \%$ & 123 & $-30 \%$ & 112 & $-36 \%$ & & & & \\
\hline Howland Main & 83 & 185 & $124 \%$ & & & & & 50 & $-40 \%$ & 34 & $-59 \%$ \\
\hline Howland West & 95 & 183 & $92 \%$ & & & & & 60 & $-37 \%$ & 48 & $-50 \%$ \\
\hline Austin Cary & 174 & 211 & $21 \%$ & 159 & $-9 \%$ & 137 & $-21 \%$ & & & & \\
\hline Donaldson & 208 & 220 & $5 \%$ & 178 & $-14 \%$ & 158 & $-24 \%$ & & & & \\
\hline Kendall & 73 & 69 & $-5 \%$ & & & & & & & & \\
\hline Audubon & 84 & 136 & $62 \%$ & & & & & & & & \\
\hline Fort Peck & 206 & 175 & $-15 \%$ & & & & & & & & \\
\hline Goodwin Creek & 117 & 84 & $-28 \%$ & & & & & & & & \\
\hline Tonzi Ranch & 77 & 74 & $-4 \%$ & 55 & $-29 \%$ & 64 & $-16 \%$ & & & & \\
\hline
\end{tabular}

${ }^{a}$ Bold values indicate the null model performance. Percentage changes in RMSE are referenced to the null model performance. The columns indicate progressive inclusion of new processes in the model.

losses) could account for the additional water being transpired. To prevent a spurious effect arising from the initial conditions, the initial water content was altered to preserve the same initial stored volume of water between all cases.

[18] The final approach was to incorporate a phenomenological representation of a saturated zone. We assumed that plant access to a water table would effectively reduce the water stress, effectively constraining $\theta>\theta_{w}$. This phenomenological approach can be readily incorporated into the modeling framework as follows:

$$
\mathrm{ET}=\mathrm{EP} \times \max \left(\frac{\left.\theta_{\min }\right|_{g w}-\theta_{w}}{\theta^{*}-\theta_{w}},\left(\frac{\theta-\theta_{w}}{\theta^{*}-\theta_{w}}\right)\right)
$$

[19] Again the output from these modified versions of the model was evaluated in terms of RMSE and AIC.

\subsection{Modification 3: Exploring Controls on Seasonality}

[20] Following the interception and water shortage corrections, the model predictions at three sites, Morgan Monroe, Howland Main Tower, and Howland West Tower, were notable for overestimating ET during the spring and autumn (e.g., the early growing season and the autumnal senescence of the trees). We broadly hypothesized two potential sources of this error: (1) the presence of an additional, significant energy sink which could reduce EP [Oliphant et al., 2004] or (2) the existence of additional hydraulic controls which would prevent the ecosystem from satisfying evaporative demand during early and late parts of the season. Energy sinks associated with canopy and vegetation heat storage have been evaluated at the Morgan Monroe State Forest and shown to be negligible components of the annual energy balance [Oliphant et al., 2004]. With this in mind we investigated the potential role of the latent heat of fusion of accumulated snow and ice in the system to act as an energy sink. To evaluate this hypothesis the excess ET during the winter and early growing season (November to June) was converted into its equivalent in water mass, allowing a direct comparison of this energy with typical depths of snow at the sites, which were obtained as water equivalents from SNODAS [National Operational Hydrological Remote Sensing Center, 2011]. To crudely simulate the effect of an energy sink, the model was re-run after reducing EP during

Table 4. Akaike Information Criteria (AIC) for the Model Output Relative to Measured ET Fluxes ${ }^{\mathrm{a}}$

\begin{tabular}{|c|c|c|c|c|c|c|c|c|c|c|c|}
\hline & \multirow{2}{*}{$\begin{array}{l}\text { Base } \\
\text { Model }\end{array}$} & \multicolumn{2}{|c|}{$\begin{array}{c}\text { Adding } \\
\text { Interception }\end{array}$} & \multicolumn{2}{|c|}{$\begin{array}{l}\text { Altering Soil } \\
\text { Depth }\end{array}$} & \multicolumn{2}{|c|}{$\begin{array}{c}\text { Adding } \\
\text { Groundwater }\end{array}$} & \multicolumn{2}{|c|}{ Energy Sink } & \multicolumn{2}{|c|}{$\begin{array}{c}\text { Growing Season } \\
\text { Index } \\
\end{array}$} \\
\hline & & AIC & Change & AIC & Change & AIC & Change & AIC & Change & AIC & Change \\
\hline Sky Oaks & 382 & 377 & $-1 \%$ & 323 & $-15 \%$ & 321 & $-16 \%$ & & & & \\
\hline Morgan Monroe & 898 & 919 & $2 \%$ & 866 & $-4 \%$ & 828 & $-8 \%$ & 821 & $-9 \%$ & 814 & $-9 \%$ \\
\hline Harvard & 219 & 242 & $10 \%$ & & & & & & & & \\
\hline Kennedy & 370 & 396 & $7 \%$ & 342 & $-8 \%$ & 325 & $-12 \%$ & & & & \\
\hline Metolius & 645 & 660 & $2 \%$ & 603 & $-7 \%$ & 594 & $-8 \%$ & & & & \\
\hline Howland Main & 459 & 544 & $19 \%$ & & & & & 407 & $-11 \%$ & 370 & $-19 \%$ \\
\hline Howland West & 472 & 542 & $15 \%$ & & & & & 437 & $-7 \%$ & 403 & $-15 \%$ \\
\hline Austin Cary & 769 & 835 & $9 \%$ & 756 & $-2 \%$ & 736 & $-4 \%$ & & & & \\
\hline Donaldson & 549 & 560 & $2 \%$ & 524 & $-5 \%$ & 514 & $-6 \%$ & & & & \\
\hline Kendall & 541 & 540 & $0 \%$ & & & & & & & & \\
\hline Audubon & 557 & 621 & $12 \%$ & & & & & & & & \\
\hline Fort Peck & 921 & 900 & $-2 \%$ & & & & & & & & \\
\hline Goodwin Creek & 483 & 457 & $-5 \%$ & & & & & & & & \\
\hline Tonzi Ranch & 443 & 445 & $0 \%$ & 410 & $-7 \%$ & 428 & $-3 \%$ & & & & \\
\hline
\end{tabular}

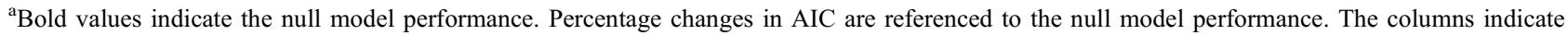
progressive inclusion of new processes in the model. 
the January-June period by a fixed rate which integrated to the discrepancy in modeled and measured LE.

[21] Evaluating the second hypothesis mechanistically is challenging given a broad range of plausible mechanisms which might impose hydraulic controls on the ecosystems. Such mechanisms include (1) soil freezing physically preventing water uptake [Hollinger et al., 1999; Waring et al., 1995], (2) low-temperatures reducing root hydraulic conductance [Aroca et al., 2001], (3) stomatal conductance reducing in response to low soil temperatures [Mellander et al., 2004], (4) increased viscosity of water [Cochard et al., 2000], (5) low stomatal conductance associated with young leaves [Hiyama et al., 2005], (6) overestimation of canopy LAI via satellite data (subcanopy and groundcover LAI may increase earlier in the season than canopy LAI) [Nemani et al., 1993; Wang et al., 2004], and (7) LAI being a poor indicator of canopy activity in evergreen forests during the early part of the growing season.

[22] Specifically addressing these mechanisms requires additional site-specific data regarding plant physiology, phenology and water use. However, a phenomenological approach that accounts for the temperature dependence of these mechanisms can be implemented using a "growing season index" (GSI) [Jolly et al., 2005]. The GSI has the following form:

$$
\begin{aligned}
\mathrm{GSI} & =0, & & \text { if } T_{s}<T_{\min } \\
& =\left(T_{s}-T_{\min }\right) /\left(T_{\max }-T_{\min }\right), & & \text { if } T_{\max }>T_{s}>T_{\min } \\
& =1, & & \text { if } T_{s}>T_{\max }
\end{aligned}
$$

where $T_{s}$ is the minimum daily soil temperature, and $T_{\min }$ and $T_{\max }$ are thresholds in minimum daily soil temperature over which plant functions are progressively less inhibited by the cold. To account for day-to-day variations in temperature the GSI is smoothed over a 30 day window. Jolly et al. [2005] suggest that for the purposes of predicting global phenology $T_{\min }$ and $T_{\min }$ could be approximated as $2^{\circ}$ and $5^{\circ} \mathrm{C}$, respectively. We approximated soil temperature by air temperature $T$, and used available soil temperature measurements to convert the $T_{s}$ thresholds proposed by Jolly et al. [2005] to air temperature thresholds. These translated into air temperature thresholds of $-5^{\circ} \mathrm{C}$ and $10^{\circ} \mathrm{C}$. Although Jolly et al. [2005] also proposed applying additional filters to the GSI on the basis of photoperiod and soil moisture, these filters are applicable to tropical and dry season deciduous sites, respectively, and can be omitted in these moist temperate sites.

\section{Results}

\subsection{Initial Model Evaluation}

[23] On the basis of the initial examination of the model performance the saturated hydraulic conductivity at Morgan Monroe State Forest and the stomatal conductance at the Austin Cary State Forest were adjusted. At Morgan Monroe the initial hydraulic conductivity $(1.2 \mathrm{~mm} / \mathrm{h})$ from the pedotransfer function led to over $40 \%$ of annual rainfall being lost as surface runoff, and model consequently underestimated annual ET by $25 \%$. An infiltration capacity of $1.2 \mathrm{~mm} / \mathrm{h}$ is inconsistent with typical values for forest soils, and Morgan Monroe soils are noted as having generally low runoff generation potential (A. Wallis, Draft resource management guide, Morgan Monroe State Forest, http://www.in.gov/dnr/ forestry/files/fo-MM_C8T1_020410.pdf), further suggesting the modeled behavior was erroneous. We replaced the $\mathrm{K}_{\text {sat }}$ values with a representative clay loam soil $K_{\text {sat }}$ of $30 \mathrm{~mm} / \mathrm{h}$ as measured in a bottomland hardwood forest at the Duke Forest Blackwood Division [Thompson et al., 2010]. At Austin Cary the parameterized vegetation produced EP values that were consistently higher than measured ET, regardless of soil water status, suggesting that EP was systematically overestimated. We attributed this to error in the vegetation parameters, and reduced the maximum stomatal conductance until peak ET modeled values under wet conditions were consistent with the tower measurements. Quantitative data describing the performance of the null model following these amendments are presented in Tables 3 and 4. RMSE values ranged from $56 \mathrm{~mm}$ at Harvard Forest to $208 \mathrm{~mm}$ at Donaldson Forest. Output from the initial model runs for four sites, Morgan Monroe State Forest (a temperate broadleaf forest), Donaldson Forest (a warm evergreen forest), Kendall Grassland (a semiarid grassland) and Tonzi Ranch (a Mediterranean savannah), is shown in Figure 2. The model performance was good at the highly water limited Kendall Forest site and fair at the mediterranean Tonzi Ranch site. Model performance at the forested sites was notably worse.

\subsection{Sensitivity Analysis}

\subsubsection{Vegetation Parameters}

[24] EP was equally sensitive with respect to LAI and $g_{s}$, so for simplicity we refer only to LAI here. The sensitivity of EP to LAI was sublinear, meaning relative changes in EP were damped compared to changes in LAI. The relationship of $\left(\mathrm{EP}_{\text {new }} / \mathrm{EP}_{\text {ref }}\right)$ to $\left(\mathrm{LAI}_{\text {new }} / \mathrm{LAI}_{\text {ref }}\right)$, where the subscript ref indicates a reference condition, was well described by a power law of the form $\left(\mathrm{EP}_{\text {new }} / \mathrm{EP}_{\text {ref }}\right)=\left(\mathrm{LAI}_{\text {new }} / \mathrm{LAI}_{\text {ref }}\right)^{\alpha_{1}}$, and the exponent $\alpha_{1}$ varied across the sites. The most sensitive site (Sky Oaks) had $\alpha_{1}=0.7$ so that a $\approx 30 \%$ error in LAI lead to $\mathrm{a} \approx 15 \%-25 \%$ error in EP. EP at the least sensitive site (Donaldson) was almost invariant with changes in LAI. In the mean, $\alpha_{1}=0.3$, so that a $30 \%$ error in LAI would generate an $8 \%-10 \%$ error in EP. As shown in Figure 3, approximately $60 \%$ of the variation in sensitivity as measured by $\alpha_{1}$ was explained by the mean annual LAI, with the most sensitive sites having lower values of LAI.

\subsubsection{Soil Type}

[25] Sensitivity to soil type was analyzed in terms of the mean pairwise change in ET between soil types pairs of sand and clay, sand and loam, and loam and clay. The variability induced by soil type was large compared to the variability induced by the vegetation parameters, leading to $20 \%-50 \%$ error in ET across the sites. Again the controls on this sensitivity were explored across all sites and are shown in Figure 3 (where the mean sensitivities for each site have been normalized to lie between 0 and 1). Approximately $50 \%$ of the variation in the sensitivity of the ET predictions to soil parameters was driven by aridity, with arid sites (Kendall, Audubon, Fort Peck, Sky Oaks and Tonzi Ranch) being most sensitive to errors in soil properties. 

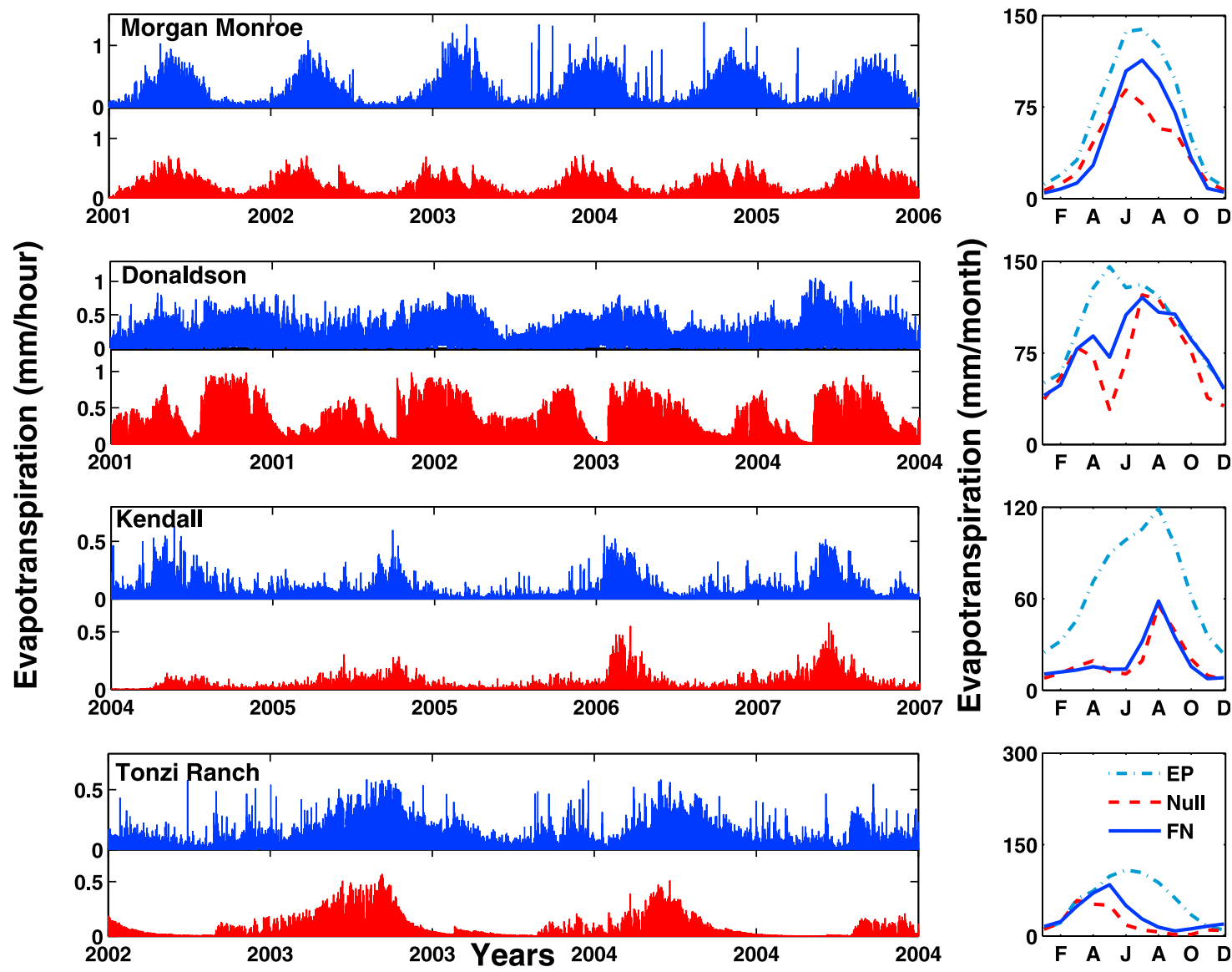

Figure 2. (left) Observations of evapotranspiration (ET; blue) at four sites with contrasting climatic drivers: Morgan Monroe (temperate forest), Donaldson (warm evergreen forest), Kendall (arid grassland), and Tonzi Ranch (Mediterranean savannah). Initial model estimation of the ET time series is shown in red. (right) The seasonal variation in ET in both modeled time series (labeled null) and the eddy covariance data (labeled FN), with the computed seasonal variability in potential evaporation (EP) included for reference.

\subsubsection{Soil Depth}

[26] Sensitivity to soil depth was analyzed by increasing and decreasing the soil depth $Z_{r}$ by factors of 2 and 3 and assessing the resulting change in the predicted values of mean annual ET. The sensitivity to changes in soil depth was sublinear and well described by power law relations between soil depth and total ET such that $\mathrm{ET}_{\text {new }} / \mathrm{ET}_{\text {ref }} \approx$ $\left(Z_{r_{\text {new }}} / Z_{r_{\text {ref }}}\right)^{\alpha_{2}}$. Across the sites the mean value of $\alpha_{2}$ was 0.18 , meaning a $30 \%$ error in soil depth translated to a $4 \%-6 \%$ change in ET. As shown in Figure 3, approximately $62 \%$ of the variation in this sensitivity is explained purely by site aridity, with arid sites being the most sensitive to changing soil depth. Note that this regression excludes two sites where increasing soil depth decreased annual ET (Kendall, where the decrease was fairly large, and Fort Peck, where the decrease was statistically indistinguishable from zero).

\subsection{Modification 1: Interception}

[27] The second column in Tables 3 and 4 indicates the change in RMSE and AIC associated with adding the interception model to the null model. At only four sites (Sky Oaks, Kendall, Fort Peck, and Goodwin Creek) did inter- ception improve both the AIC and the RMSE, and this improvement was marginal at Kendall. At all other sites the addition of interception either worsened the performance of the model or failed to improve the model AIC. Model output following this modification is shown in Figure 4.

\subsection{Modification 2: Additional Water Sources}

\subsubsection{Bulk Water Balance of Water Short Sites}

[28] $P>$ ET, at all the sites where the model indicated water shortages (Sky Oaks, Morgan Monroe, Kennedy, Metolius, Austin Cary, Donaldson, and Tonzi Ranch; see boxed plots in Figure 4), indicating that the annual rainfall was sufficient to supply annual evapotranspiration (see Table 5). However, at several of the sites ET $\approx P$, with nearly $100 \%$ of the rainfall volume partitioned to ET at Metolius and $\approx 90 \%$ at Donaldson.

\subsubsection{ET and Soil Moisture Comparison}

[29] Examination of the time series of ET and soil moisture was illuminating at several sites where ET persisted even when the measured soil moisture was lower than wilting point. This phenomenon was reported at Tonzi Ranch by Miller et al. [2007] and is also well illustrated at 

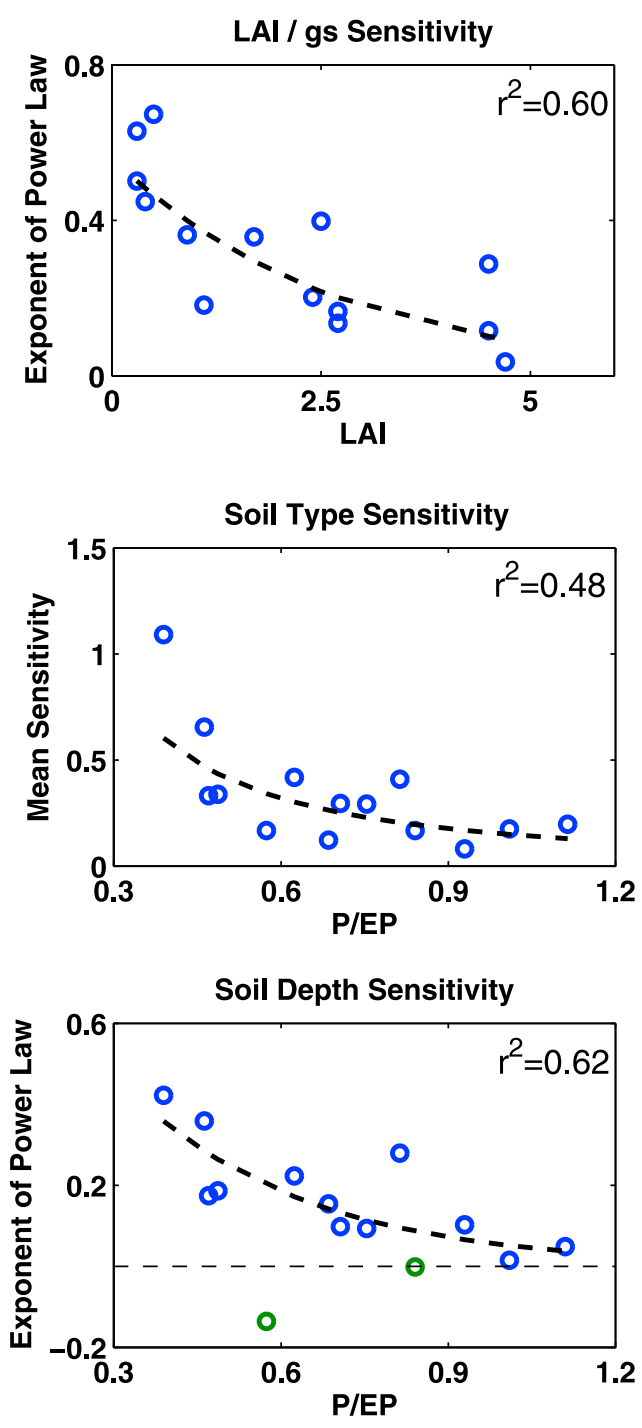

Figure 3. Sensitivity of model predictions to soil and vegetation parameters. The sensitivity (measured by the variables shown on the $y$ axis) was computed from the response of (top) EP to LAI and ET to (middle) soil type and (bottom) soil depth. The sensitivity of EP to vegetation parameters is greatest for sites with sparse vegetation and declines as canopies saturate. The sensitivity of ET to soil type and depth are greatest in arid climates $(P / \mathrm{EP} \ll 1)$, where the capacity of the soil to store moisture is a critical determinant of transpiration. In each case, climatic or vegetation parameters explain $50 \%$ or more of the variation in sensitivity to parameters between sites, potentially offering a useful basis for estimating uncertainty or guiding the importance of making additional parameter measurements.

the Sky Oaks chapparal site, as shown in Figure 5. Sky Oaks is located on thin, poor soils in southern California. Soil depth is reportedly $\approx 20-40 \mathrm{~cm}$, and soil moisture is reported for the surface soils. Tight coupling would be expected between surface soil moisture and evapotranspiration in this ecosystem, and indeed such tight coupling is often observed. However, over at least two extended periods (1-2 months in duration), ET increased while soil moisture declined sharply, suggesting that transpiration was maintained by alternative water sources. Indeed for much of the time series
ET is sustained, although often at low rates, when measured surface soil moisture was lower than wilting point.

3.4.3. Deep Drainage Losses and Increased Soil Depth

[30] Deep drainage losses formed a substantial portion of the null model water balance for all seven sites where the model results indicated signatures of water stress. Deep drainage ranged from $36 \%$ of $P$ at Austin Cary to $61 \%$ at Sky Oaks (see Table 5). When drainage losses were mitigated by increasing the soil and rooting depth in the model, drainage losses fell by 13 to $73 \%$ with accompanying increases in ET and storage. Model predictions of ET outperformed the null model in terms of RMSE and AIC. RMSE fell between 9\% (Austin Cary) and 46\% (Sky Oaks), with a mean improvement of $26 \%$ across the seven sites. AIC and RMSE values are shown in Tables 3 and 4. Figure 6 shows model output in terms of a time series of monthly ET for the seven sites where the null model indicated water shortages.

\subsubsection{Effect of Constant Groundwater Supply}

[31] A constant groundwater supply was simulated using equation (5). The values of $\left.\theta_{\min }\right|_{g w}$ used in the model are shown in Table 2. The addition of a groundwater term improved the model results in terms of both RMSE and AIC at all sites, and did so on average more than simply increasing the soil depth (except Tonzi Ranch where the depth increase produced a better result). RMSE fell relative to the null model by between $16 \%$ (Tonzi Ranch) and 50\% (Sky Oaks), with a mean improvement of 34\% across the seven sites. Model output in terms of a time series of monthly ET is shown in Figure 6.

\subsection{Modification 3: Exploring Controls on Seasonality}

[32] For the three sites (Morgan Monroe, Howland Main Tower, and Howland West Tower) where phase issues were evident in the model, the total energy discrepancy in terms of mean cumulative latent heat fluxes for the NovemberApril period is shown in Table 6. The approximate deviation in latent heat fluxes (expressed in terms of capacity to melt ice) is comparable to typical depths of snowfall during the winter period, suggesting that snowmelt might provide a sufficient energy sink to explain the discrepancy. However, crudely modeling this additional energy sink by reducing available energy was insufficient to reconcile model and measured ET time series, although model results did improve (reducing RMSE by $7 \%$ at Morgan Monroe, $40 \%$ at Howland Main and 37\% at Howland West). The use of the GSI to phenomenologically capture the dependence of ET also improved the model performance (reducing RMSE by $11 \%$ at Morgan Monroe, $59 \%$ at Howland Main and $50 \%$ at Howland West). Note that this is without any calibration of the GSI thresholds beyond those suggested by Jolly et al. [2005]. The GSI resolved the seasonality issues in the model compared to the measured data better than the incorporation of an additional energy sink in the model. Neither an additional energy sink nor the GSI were needed to explain the fluxes at the Harvard Forest site, an otherwise comparable temperate forest.

\subsection{Multiple Time Scale Analysis}

[33] Siqueira et al. [2006] and Mahecha et al. [2010] have shown the value in undertaking comparisons of model performance not simply in the time domain but also the frequency domain, allowing a comparison of variability 


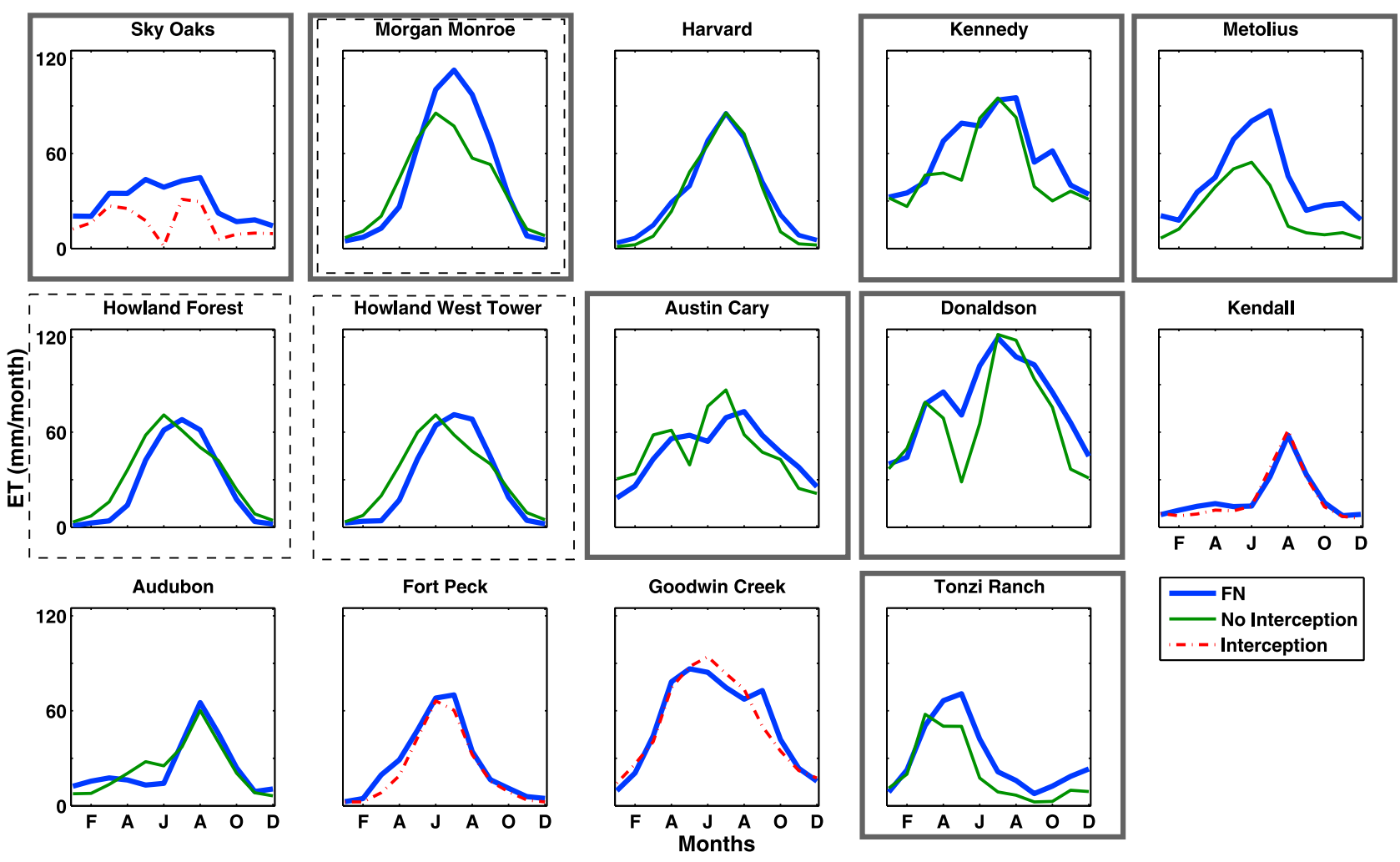

Figure 4. Output of the null model (including corrections to soil type at Morgan Monroe and vegetation properties at Austin Cary). Data shown are the mean monthly ET values for the simulated and measured time series. Thick blue lines indicate measured values (FN), solid green lines indicate a null model with no interception component (no interception), and dashed red lines indicate a null model including an interception component (interception). Grey boxes indicate sites where significant underestimation of ET occurs and that are hypothesized to experience less water stress in reality than in the model environment. Dashed boxes indicate sites where lags in the phase of ET between measured and modeled ET were found (Morgan Monroe, Harvard, and Howland sites). The four unboxed sites (Kendall, Audubon, Fort Peck, and Goodwin Creek) appear to have their seasonality well represented by the model output.

as well as the magnitude of predicted fluxes. This comparison is shown in Figure 7. It is apparent that the models generally did not capture the high-frequency variation in ET but nonetheless reproduced the low-frequency variations reasonably well. Examination of the power spectra enables us to localize (in frequency space) the source of error in the model output: as shown in Figure 7, the key deviations in modeled and measured ET at Sky Oaks and Kennedy Space Center are localized at frequencies of $\approx 1 / 30$ days, the monthly time scale that was targeted throughout this study.

\section{Discussion}

\subsection{Null Model Performance}

[34] ET variability on seasonal-annual-interannual time scales is important for many aspects of hydrological prediction. From this study it is evident that prediction at this time scale is feasible using minimal energy balance models such as the Penman-Monteith equation coupled to one dimensional soil moisture models, and that this approach is most robust at water-limited sites with shallow-rooted vegetation. At sites with deeper-rooted vegetation, subsurface water storage, accumulation and depletion lead to sensitivity in the description of the deep soil structure and moisture dynamics. This is likely to be problematic for the purposes of modeling poorly studied sites because of the challenges associated with characterizing these soil zones and root distributions. At sites with stronger energy limitation, moreover, the simple model used here overestimated early and late season transpiration.

[35] The failure of the null model to capture highfrequency dynamics (as illustrated in Figure 7) is unsurprising given that the model did not resolve the dynamics of stomatal regulation and altering canopy conductance [Siqueira et al., 2006]. However the fact that the model nonetheless captured the seasonal-annual dynamics reasonably well suggests that the propagation of information from subdaily to seasonal time scales was limited, at least for ET prediction. The discrimination between the power spectra of different models on time scales of $\approx 30$ days suggests that focus on monthly time scales was an appropriate way to interrogate the performance of the model. 
Table 5. Water Balance Data for the Seven Sites Where the Model Indicated Plant Water Shortages ${ }^{\text {a }}$

\begin{tabular}{lcccc}
\hline \multicolumn{1}{c}{ Site } & $\begin{array}{c}\text { Annual } \\
\text { PPT } \\
(\mathrm{mm})\end{array}$ & $\begin{array}{c}\text { Annual } \\
\text { ET } \\
(\mathrm{mm})\end{array}$ & ET/PPT & $\begin{array}{c}\text { Drainage in } \\
\text { Null Model } \\
(\% \text { PPT })\end{array}$ \\
\hline Sky Oaks & 484 & 352 & 0.73 & $61 \%$ \\
Morgan Monroe & 1081 & 540 & 0.50 & $54 \%$ \\
Kennedy & 1131 & 835 & 0.74 & $58 \%$ \\
Metolius & 499 & 492 & 0.99 & $52 \%$ \\
Austin Cary & 811 & 574 & 0.71 & $36 \%$ \\
Donaldson & 1065 & 946 & 0.89 & $38 \%$ \\
Tonzi Ranch & 572 & 363 & 0.64 & $44 \%$ \\
\hline
\end{tabular}

${ }^{\mathrm{a}}$ Columns indicate measured mean rainfall, evapotranspiration, and aridity over the modeled period indicated in Table 1 and the predicted proportion of annual rainfall lost from the rooting zone as deep drainage in the null model.

\subsection{Parameter Sensitivity}

[36] Estimating vegetation and soil parameters at individual sites is challenging in the absence of site specific measurements, making sensitivity analysis of these sources of uncertainty important. For instance, saturation of remotely sensed vegetation indices such as NDVI as LAI increases is considered one of the primary challenges with accurately estimating LAI from remote sensing [Davi et al., 2006]. These analyses suggest that this uncertainty at high LAI may be mitigated to some extent by the reduced sensitivity of EP to LAI as LAI increases. Conversely, robust estimation of LAI and stomatal conductance parameters is increasingly important in sparse canopies. Accurate characterization of the parameters determining soil storage also appears to be most important in arid sites, where vegetation access to water is strongly determined by the behavior of water stored in the soil profile, in comparison to wetter sites where regular rainfall replenishes soil stores, and energy availability provides a greater constraint on evapotranspiration. On the basis of the implications for the predictive capacity of models this suggests that efforts in parameter estimation would be best focused on xeric to mesic ecosystems with relatively sparse canopies. The sensitivity of surface energy and water balance to both physical and biological parameters in drier sites may explain why recent model-data syntheses of carbon dynamics across multiple Ameriflux sites identified model performance as generally being poorer in grasslands and savannahs than in temperate forests [Schwalm et al., 2010].

[37] Given this sensitivity analysis the fact that the null model performed best in relatively arid sites with sparse canopies seems counterintuitive, and speaks strongly to the importance of the dynamics of water availability, particularly to deep-rooted species, in driving the seasonal patterns of ET. The commonality between the grassy and arid sites is (1) relatively shallow rooting depths, and (2) where root depths are greater (e.g., at Audubon Ranch), the fact that intermittent rainfall rarely wets the deep soil zones means that provided the dynamics of the shallow soil zone are well simulated the model performs relatively well. By contrast, in dry sites where plants are deep-rooted and there is potential for significant deep drainage during winter rains (e.g., Tonzi, Sky Oaks, and Metolius), the null model performed poorly.

\subsection{Subsurface Structure and Water Availability}

[38] The improvements in model performance when soil depth was increased or when a groundwater flux term was included strongly suggest that plant access to water outside

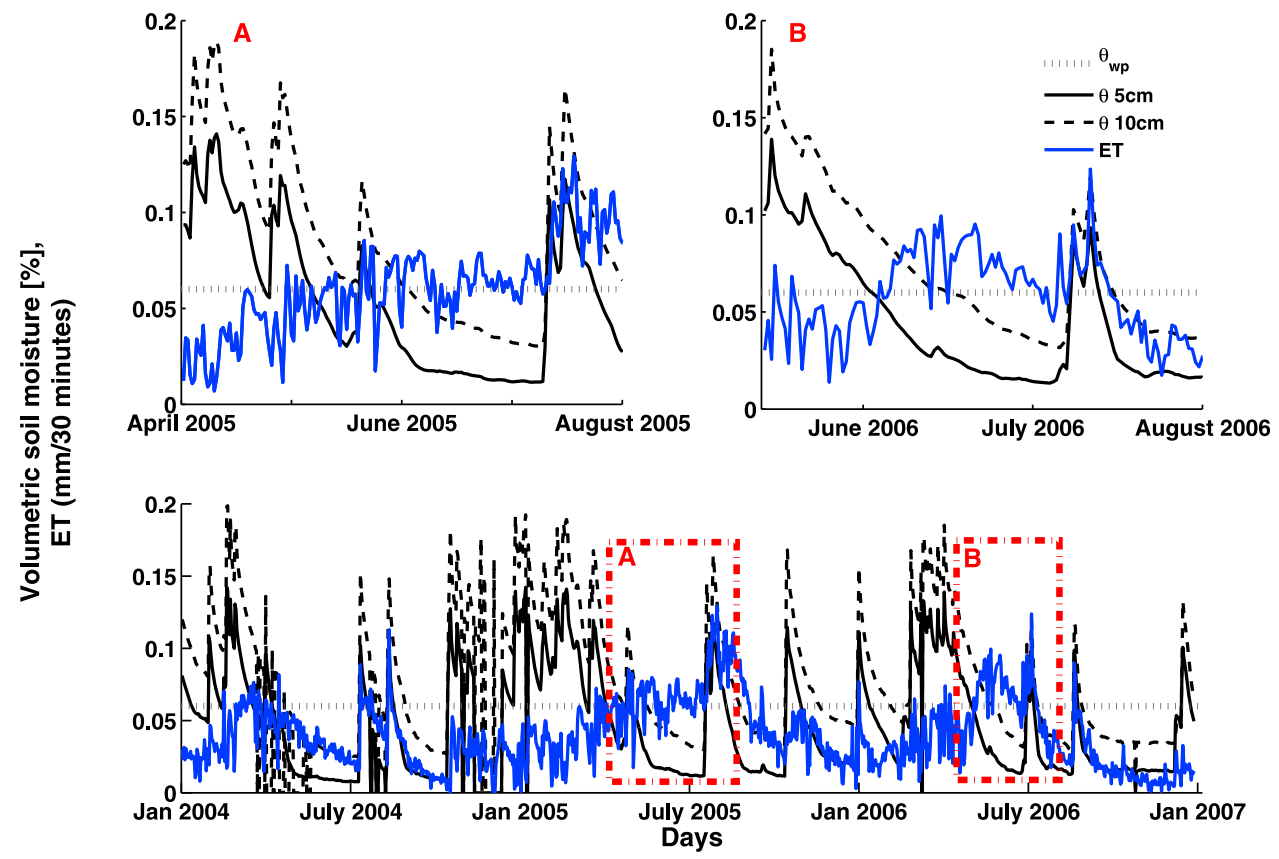

Figure 5. Time series of soil moisture and ET measurements at Sky Oaks, California. Two separate periods, lasting 1-2 months, can be identified in the record where ET increases despite a sustained decline in soil moisture, which drops below the wilting point for soils at the site (wilting point shown as the $\theta_{w p}$ dotted grey line). Given the shallow soils at the site, this indicates that the tree species are accessing additional water resources that are not subject to the same drying dynamics as the surface soil moisture reservoir. 

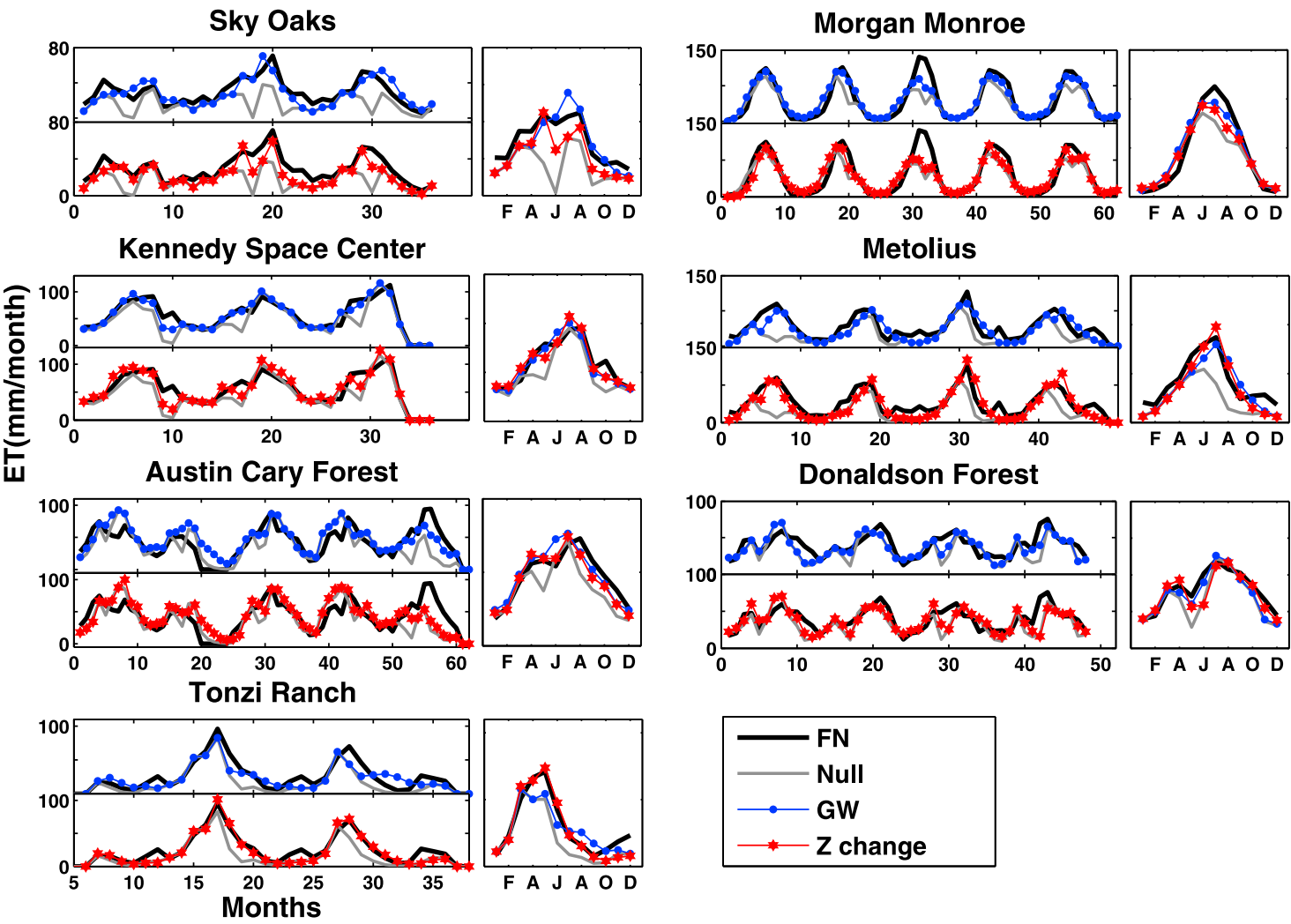

Figure 6. Amending the null model with additional water sources: either provided by increased soil depth or by adding a groundwater source term. The ET time series for each site aggregated to the monthly level is shown in the main plots. The inserts on the right show the progression for the "mean year." All sites shown here exhibited features of water stress in the null model output, as shown in Figure 4.

the vadose zone is a critical driver of ET dynamics at several of the sites investigated. An intriguing feature of the model output illustrated in Figure 6, and particularly obvious at, e.g., Sky Oaks, is that during certain times of the year the model modification associated with increased soil depth lead to greater improvements in ET prediction than the groundwater amendment, while at other times of the year the groundwater amendment lead to greater improvements in ET prediction. One plausible explanation for the observation that measured ET was bounded by these two modes of water availability is that both processes operate. The presence of a deep occluding layer, for instance, could lead to the availability of a relatively large water store at low water potential, comparable to the modeled cases with increased soil depth. As this store filled, a saturated zone could develop above any occluding layer, leading to the formation of a capillary fringe and a low-potential water supply to the deep roots, comparable to the groundwater amendment applied in the model. The existence and volumes stored in such a perched water table would vary through time, so the two descriptions employed here, a deep soil reserve versus a plant-available water table, could both apply at different times of year. Thus there may be no need to invoke an external groundwater supply to explain the ET dynamics, but only the dynamics of perched water table formation and depletion.

[39] Data supporting this mechanism are available at several of the sites. Powell et al. [2005] documented the presence of a shallow water table at Austin Cary which was utilized by the pines to sustain ET during drought periods. Similar shallow water table conditions prevail at the Kennedy site [Schmalzer and Hinkle, 1990], and, given the presence of the shallow surficial aquifer in the proximity of Donaldson [Green et al., 1989], trees there may also have periodic access to a perched water table. Transpiration at Metolius has been shown to be sustained by hydraulic redistribution from deep soil layers, meaning moisture dynamics in the deeper soils are likely to be important constraints on ET [Thomas et al., 2009]. By contrast, it is not believed that there are groundwater resources available at the Morgan Monroe site (H. P. Schmid and D. Dragoni, personal communication, 2010). However, other studies

Table 6. Discrepancy Between Modeled and Measured Latent Heat Fluxes for the November-April Period for Three Sites, Represented in Terms of Energy and Equivalent Depth of Water as Determined by the Latent Heat of Fusion ${ }^{\text {a }}$

\begin{tabular}{lccc}
\hline \multicolumn{1}{c}{ Site } & $\begin{array}{c}\Delta \text { Latent } \\
\text { Heat } \\
\left(\mathrm{MJ} / \mathrm{m}^{2}\right)\end{array}$ & $\begin{array}{c}\text { Water } \\
\text { Melt } \\
(\mathrm{mm})\end{array}$ & $\begin{array}{c}\text { Mean } \\
\text { Snow } \\
(\mathrm{mm})\end{array}$ \\
\hline Sky Oaks & 0.06 & 180 & 130 \\
Morgan Monroe & 0.07 & 200 & 240 \\
Kennedy & 0.07 & 210 & 240 \\
\hline
\end{tabular}

${ }^{a}$ SNODAS data for the sites, averaged for the periods of data availability between 2002 and 2010, are shown for comparison. 

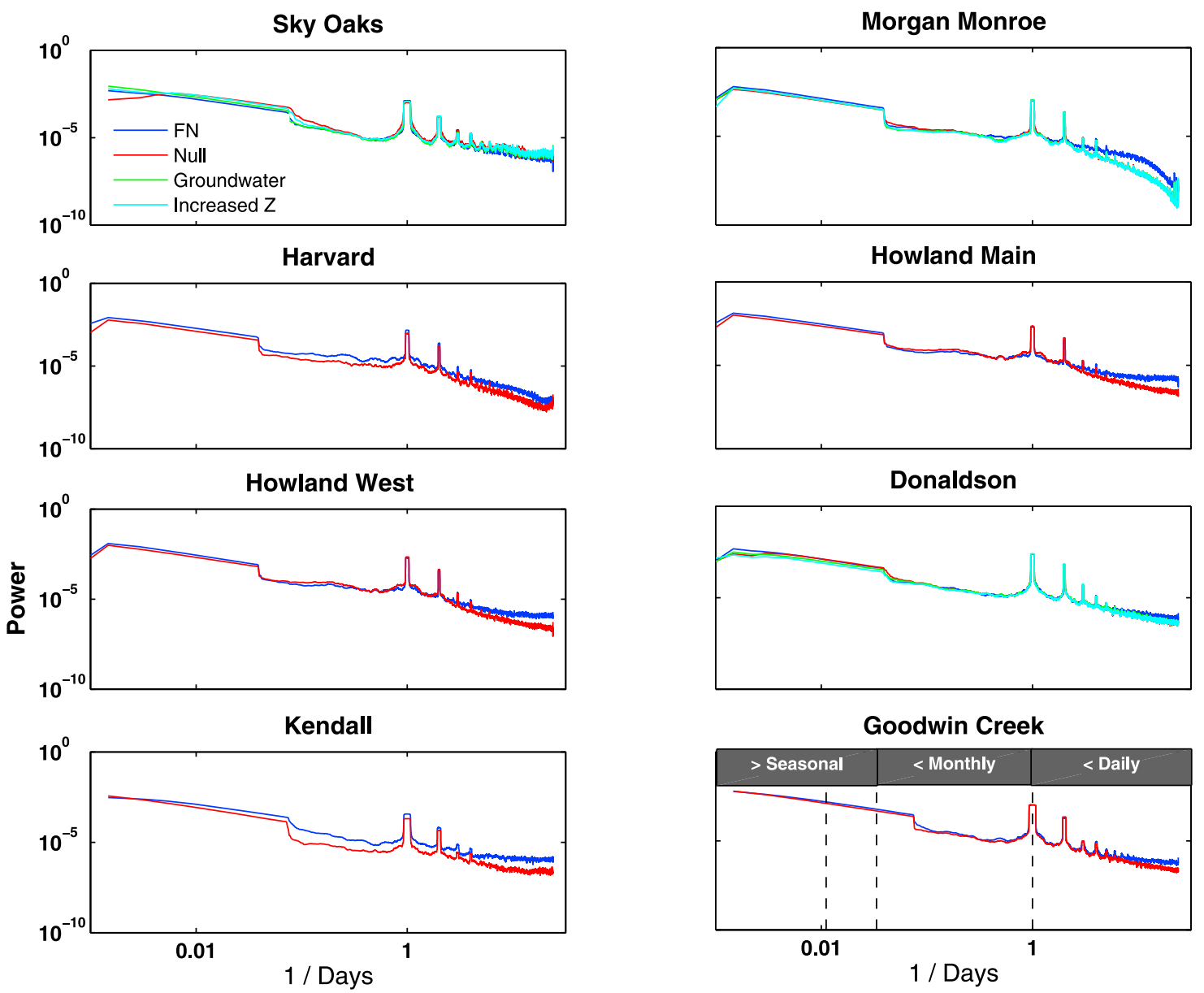

Figure 7. Fourier power spectra of the ET signatures across a subset of sites chosen to represent the climatic and vegetation variability in the data set. Clear deviations in the spectra are seen at subdaily scales, potentially attributable to the lack of a dynamic treatment of the stomatal conductance scheme and to variations in tower footprint. Increasing agreement in the spectra arises from daily to annual scales.

have also invoked additional water sources to explain evapotranspiration dynamics Morgan Monroe. For example, Stöckli et al. [2008] found that reproduction of water and energy balance at Morgan Monroe in the Community Land Model were improved when a groundwater term was incorporated into the site description. Reconciling multiple model failures to reproduce ET at Morgan Monroe without a groundwater source term with the absence of groundwater at the site is problematic. It may suggest complex patterns of soil depth and water availability in the tower footprint, or potentially a capacity for the underlying bedrock to store plant available water. In the absence of further detailed hydrological investigations at the site it may not be possible to resolve this issue.

[40] The best test of the model predictions in regard to groundwater dynamics is available at Tonzi Ranch where Miller et al. [2010] computed the contribution of local groundwater stores to transpiration at the site in 2007-2008, allowing us to compare the predictions of the model with site specific estimates (although note that the model runs were undertaken for 2002-2004, so that we compare the mean seasonality of groundwater uptake predictions against the Miller et al. [2010] data). The model output used for this comparison was the doubling of soil depth at Tonzi, which produced the best fit to the observed ET seasonality, with results shown in Figure 8 . The model predicts that approximately $60 \mathrm{~mm} / \mathrm{yr}$, or around $30 \%$ of annual ET, is contributed to transpiration from ground water sources. This compares well with the estimates of Miller et al. [2010], who found that approximately $23 \%$ of annual ET was associated with groundwater uptake. The groundwater contribution from the model was centered on a peak over the months of JuneAugust, with groundwater ET rates during this period of approximately $0.4 \mathrm{~mm} / \mathrm{d}$, which again compare favorably with uptake rates of $0.25-0.4 \mathrm{~mm} / \mathrm{d}$ reported by Miller et al. [2010]. The deep drainage behavior was also reasonably well reproduced in the model, with peak recharge occurring from December to March. Modeled recharge was $220 \mathrm{~mm} / \mathrm{yr}$, which exceeds the measurements of $\approx 150 \mathrm{~mm} / \mathrm{yr}$. Similarly, the model overestimated groundwater contributions to ET early in the growing season and underestimated them later in the growing season. Discrepancies of this sort are expected given the crude treatment of the subsurface structure, rooting distributions and phenological controls in the model, and the fact that the modeled period did not coincide with the period of Miller et al. [2010] measurements. Overall, however, the similarity between the modeled and measured data is encouraging. 


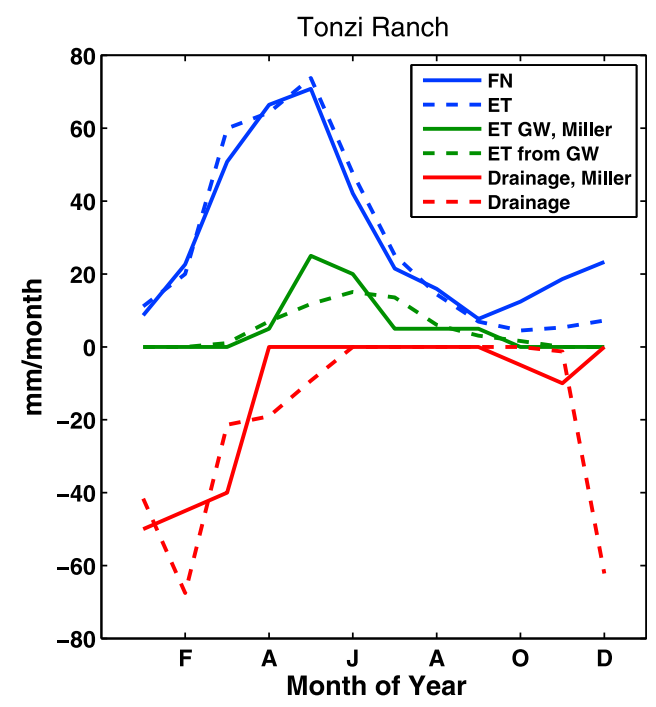

Figure 8. Comparison of the total ET fluxes measured at Tonzi Ranch with the model predictions (blue lines), the proportion of ET supplied by groundwater (green solid and dashed lines), and the recharge at the site (red solid and dashed lines). Measured data are from Miller et al. [2010] for the 2008 period. Modeled data are for 20022004 (the period where ground-based leaf area index measurements were available).

[41] Regardless of the precise mechanism, the results suggest that hydrological controls on ET extend beyond the identified rooting zone or soil depth in many sites, and that the dynamics of deep water movement, storage and depletion should be accounted for. The results also suggest that simple models can identify signatures of groundwater or deep soil moisture controls on ET, potentially providing a useful diagnostic for ET source partitioning. Full validation of these model implications is inhibited at many AmeriFlux sites because of limited data about soil structure at depth and because of the absence of sufficient data to close the water balance at the site. Installing piezometer arrays and nested soil moisture sensors through the full soil depth at existing eddy correlation towers would significantly improve their utility for hydrological studies. Further hydrological amendments to the AmeriFlux network, such as colocating towers with stream gauges in lower-order watersheds, would offer valuable insight into scaling of water balance dynamics from patches to watershed scales. This would offer important insight into the causal links between streamflow dynamics and ET, the significance of lateral transport processes in governing ET, and the interaction of these processes with vegetation dynamics.

\subsection{Additional Controls on Seasonality}

[42] The poor performance of the model in representing the phase of ET throughout the growing season at Howland Forest and Morgan Monroe is an outstanding problem. Both hypotheses invoked, namely, the potential role of snow as an energy sink or the role of temperature in altering the site hydraulic behavior, appear plausible. In neither case was sufficiently mechanistic modeling undertaken to resolve the true feasibility of these mechanisms in explaining the discrepancies in spring and autumnal ET model predictions and tower measurements. Although not mechanistic the good performance of the growing season index in amending ET fluxes without parameter tuning was notable. In the absence of detailed understanding of energy partitioning and hydraulics at a site during the spring or autumn period, the results suggest that the GSI may provide a reasonable phenomenological approach to improving ET estimates. It is also worth noting that the challenge of prediction during these seasons is not unique to the MWF-PM model. Many land surface models, including those with sophisticated energy balance schemes experience difficulties in reproducing land-atmosphere fluxes during spring and autumn [Schwalm et al., 2010]. These additional dynamics were not necessary to predict the ET seasonality at Harvard Forest, despite similar climatic conditions, making it appealing to speculate that the strong signal of seasonality at Howland Forest might be related to its preponderance of evergreen canopy species, and the difficulty of using LAI as a proxy for canopy activity of these sites in early spring or late autumn. However, given the plethora of potential mechanisms that

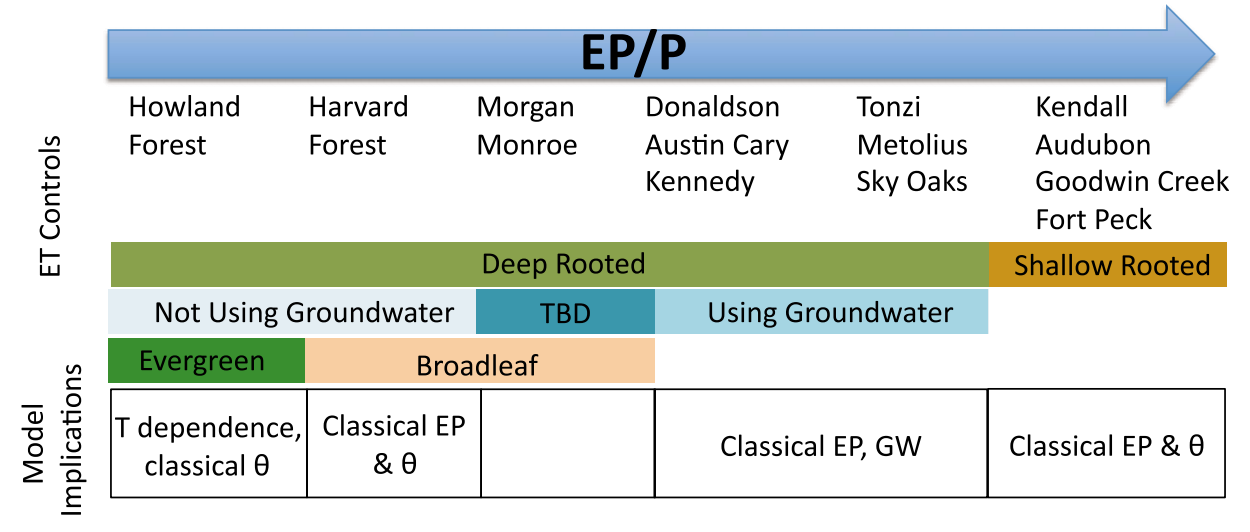

Figure 9. Classification scheme for the 14 sites considered in this study. Controls on ET organize across an aridity gradient and organize further in terms of rooting depth and controls on early and late season EP. Morgan Monroe water use is indicated as to be determined (TBD) to recognize the ongoing need to resolve multiple model results with site-based information. 
might be involved in altering flux dynamics during spring and autumn, disaggregating cause and effect further at these sites is likely to require further field-based investigation.

\section{Conclusion}

[43] The model results are suggestive of strong controls of climate and soil on the seasonal patterns of ET. They highlight the potential to capture ET dynamics readily in simple models and to use simple models to interrogate data and draw inferences about processes operating at different sites. In contrast to the recent data-model synthesis undertaken by Schwalm et al. [2010], where model performance was best in forests and worst in water-limited sites, the overall performance of the PM-MWF model was most robust in water-limited sites and generally most confounded in forested ecosystems. This potentially reflects the fact that Schwalm et al. [2010] evaluated their models in terms of carbon efflux rather than ET, or may reflect the value of simple models with fewer parameters for ET prediction.

[44] Although one of the motivations of this work was to explore possible temporal connections with the emergent uniformity observed in the Horton index, the results are as suggestive of differences between sites as they are of commonalities, making the collapse of variability reported by Troch et al. [2009] all the more surprising. S. Zanardo et al. (Climatic and landscape controls on interannual variability of catchment water balance: A stochastic approach, submitted to Water Resources Research, 2011) showed that many features of the relationship between aridity and the proportional use of vegetation can be explained by a 1-D soil model incorporating stochasticity in rainfall but not seasonality in rainfall, vegetation or ET response. Although this approach captured the temporal mean behavior of the catchment water balance well, interannual variability in the water balance was more poorly described. It is tempting to attribute such interannual variation to the deviations of seasonality in water, energy and vegetation from a mean field condition as simulated by Zanardo et al. (submitted manuscript, 2011). The phase and seasonality in rainfall and temperature, as mediated by the soil store had a strong signal in the ET dynamics that emerged within years and between sites in this analysis. Future work will utilize the modeling approaches developed here to investigate how seasonal variability propagates to interannual variation in water balance, as the next step in exploring the emergence of the stationary Horton index.

[45] The results presented here are suggestive of components of a catchment classification scheme based on emergent process controls on the properties of the hydrological filter of catchments. Such a process-based approach would complement existing, largely statistically driven approaches to catchment classification [McDonnell and Woods, 2004; Detenbeck et al., 2000; Caratti et al., 2004] and has strong analogies with recent approaches based on catchment "functionality" [Sawicz et al., 2010], although to date, such approaches have focused on the features of streamflow. As illustrated in Figure 9, the AmeriFlux sites considered here appear to broadly cluster across aridity gradients, with secondary controls arising on the basis of rooting depth (which determines the potential for water table dynamics to interact with ET at a site) and, in energy-limited sites, the suite of controls that determine the behavior of early season ET. More nuanced approaches to this classification may be possible, for instance, by factoring in controls such as stand age, which may predict the degree of plant investment in deep root structure [Stoy et al., 2006], or specific phenological controls on stomatal activity and plant hydraulic conductance. Full elucidation of more detailed controls on ET increasingly highlight the active role of vegetation physiology and adjustment of hydraulic fluxes as determinants of water balance.

[46] Acknowledgments. This study was conducted under the auspices of the University of Illinois at Urbana Champaign's Hydrological Synthesis Project, NSF EAR 06-36043, and supported by its principle investigator, M. Sivapalan. The authors thank Ben Ruddell for his input in organizing the work. S. Thompson was supported by NSF grants EAR-0628342 and EAR-063578. The authors thank the AmeriFlux principle investigators for data access. Principle investigators were invited to review this manuscript prior to submission and were contacted to request data access prior to publication. We thank Russell Scott, Darrel Jenerette, Hans Peter Schmid, and Danilo Dragoni for their constructive feedback on the draft manuscript. B. Law's Oregon Metolius flux sites were supported by the Office of Science (BER), U.S. Department of Energy (DOE, grant no. DE-FG02-06ER64318), and H. P. Schmid and D. Dragoni's Morgan-Monroe flux site was provided by the Office of Science (BER), U.S. Department of Energy, through the Midwestern Center of the National Institute for Global Environmental Change (NIGEC), the National Institute for Climate Change Research (NICCR), and the Terrestrial Carbon Program (TCP).

\section{References}

Aroca, R., F. Tognoni, J. Irigoyen, M. Sanchez-Diaz, and A. Pardossi (2001), Different root low temperature response of two maize genotypes differing in chilling sensitivity, Plant Physiol. Biochem., 39(12), 1067-1073.

Baldocchi, D., and S. Ma (2011), Tonzi Ranch Tower FLUXNET L3 and L4 data, ftp://cdiac.ornl.gov/pub/ameriflux/data/Level4/Sites_ByName/ Tonzi_Ranch/, Carbon Dioxide Inf. Anal. Cent., Oak Ridge Natl. Lab., Oak Ridge, Tenn.

Basu, N., P. Rao, H. Winzeler, S. Kumar, P. Owens, and V. Merwade (2010), Parsimonious modeling of hydrologic responses in engineered watersheds: Structural heterogeneity versus functional homogeneity, Water Resour. Res., 46, W04501, doi:10.1029/2009WR007803.

Betts, A. K., J. H. Ball, A. C. M. Beljaars, M. J. Miller, and P. A. Viterbo (1996), The land surface-atmosphere interaction: A review based on observational and global modeling perspectives, J. Geophys. Res., 101(D3), 7209-7225.

Blyth, E., J. Gash, A. Lloyd, M. Pryor, G. Weedon, and J. Shuttleworth (2010), Evaluating the JULES land surface model energy fluxes using FLUXNET Data, J. Hydrometeorol., 11, 509-519, doi:10.1175/ 2009JHM1183.1.

Caldwell, M., H. Meister, J. Tenhunen, and O. Lange (1986), Canopy structure, light microclimate and leaf gas exchange of Quercus coccifera $\mathrm{L}$. in a Portuguese macchia: Measurements in different canopy layers and simulations with a canopy model, Trees, 1, 25-41.

Caratti, J. F., J. A. Nesser, and C. L. Maynard (2004), Watershed classification using canonical correspondence analysis and clustering techniques: A cautionary note, J. Am. Water Resour. Assoc., 40(5), 1257-1268.

Cochard, H., R. Martin, P. Gross, and M. Bogeat-Triboulot (2000), Temperature effects on hydraulic conductance and water relations of Quercus robur L., J. Exp. Bot., 51(348), 1255-1259.

Comstock, J. P., and J. S. Sperry (2000), Theoretical considerations of optimal conduit length for water transport in vascular plants, New Phytol., 148(2), 195-218.

Davi, H., K. Soudani, T. Deckx, E. Dufrene, V. Le Dantec, and C. Francois (2006), Estimation of forest leaf area index from SPOT imagery using NDVI distribution, Int. J. Remote Sens., 27(5-6), 885-902.

Detenbeck, N. E., S. L. Batterman, V. J. Brady, J. C. Brazner, V. M. Snarski, D. L. Taylor, J. A. Thompson, and J. W. Arthur (2000), A test of watershed classification systems for ecological risk assessment, Environ. Toxicol. Chem., 19(4), 1174-1181.

Dickinson, R. E., A. Henderson, C. Rosenzweig, and P. J. Sellers (1991), Evapotranspiration models with canopy resistance for use in climate models-A review, Agric. For. Meteorol., 54(2-4), 373-388. 
Dragoni, D., C. Grimmond, J. Randolph, H. Schmid, and H.-B. Su (2009), Morgan Monroe Forest FLUXNET L3 and L4 Data, ftp://cdiac.ornl.gov/ pub/ameriflux/data/Level4/Sites ByName/Morgan Monroe State Forest/, Carbon Dioxide Inf. Anal. Cent., Oak Ridge Natl. Lab., Oak Ridge, Tenn.

Drake, B., R. Hinkle, J. Li, and T. Powell (2009), Kennedy Space Center Scrub Oak FLUXNET Site L3 and L4 Data, ftp://cdiac.ornl.gov/pub/ ameriflux/data/Level4/Sites_ByName/Kennedy_Space_Centere_Scrub Oak/, Carbon Dioxide Inf. Anal. Cent., Oak Ridge Natl. Lab., Oak Ridge, Tenn.

Falge, E., et al. (2005), Comparison of surface energy exchange models with energy flux data in forest and grassland ecosystems of Germany, Ecol. Modell., 188, 174-216, doi:10.1016/j.ecolmodel.2005.01.057.

Feddes, R. A., et al. (2001), Modeling root water uptake in hydrological and climate models, Bull. Am. Meteorol. Soc., 82(12), 2797-2809.

Fisher, J. B., T. A. DeBiase, Y. Qi, M. Xu, and A. H. Goldstein (2005), Evapotranspiration models compared on a Sierra Nevada forest ecosystem, Environ. Modell. Software, 20(6), 783-796.

Fisher, J. B., K. P. Tu, and D. D. Baldocchi (2008), Global estimates of the land-atmosphere water flux based on monthly AVHRR and ISLSCP-II data, validated at 16 FLUXNET sites, Remote Sens. Environ., 112(3), 901-919.

Food and Agricultural Organization (1998), Crop evapotranspirationGuidelines for computing crop water requirements, FAO Irrig. Drain. Pap. 56, Rome.

Goldberg, V., and C. Bernhofer (2001), Quantifying the coupling degree between land surface and the atmospheric boundary layer with the coupled vegetation-atmosphere model HIRVAC, Ann. Geophys., 19, 581-587.

Green, R., J. Duncan, T. Seal, J. M. Weinberg, and F. Rupert (1989), Characterization of the sediments overlying the Floridan aquifer system in Alachua County, Florida, Open File Rep. 29, Fla. Geol. Surv., Tallahassee. [Available at http://aquaticcommons.org/1480/.]

Green, S. R., M. B. Kirkham, and B. E. Clothier (2006), Root uptake and transpiration: From measurements and models to sustainable irrigation, Agric. Water Manage., 86(1-2), 165-176.

Hamza, M. A., S. H. Anderson, and L. A. G. Aylmore (2001), Studies of soil water drawdowns by single radish roots at decreasing soil water content using computer-assisted tomography, Aust. J. Soil Res., 39(6), $1387-1396$.

Hiyama, T., K. Kochi, N. Kobayashi, and S. Sirisampan (2005), Seasonal variation in stomatal conductance and physiological factors observed in a secondary warm-temperate forest, Ecol. Res., 20(3), 333-346.

Hollinger, D. (2009), Howland West Tower FLUXNET L3 and L4 Data, ftp://cdiac.ornl.gov/pub/ameriflux/data/Level4/Sites_ByName/Howland Forest West Tower/, Carbon Dioxide Inf. Anal. Cent., Oak Ridge Natl. Lab., Oak Ridge, Tenn.

Hollinger, D., S. Goltz, E. Davidson, J. Lee, K. Tu, and H. Valentine (1999), Seasonal patterns and environmental control of carbon dioxide and water vapor exchange in an ecotonal boreal forest, Global Change Biol., 5(8), 891-902.

Hollinger, D., B. Dail, E. Davidson, B. Evans, M. Leclerc, J. Lee, and A. Richardson (2009), Howland Main Tower FLUXNET L3 and L4 Data, ftp://cdiac.ornl.gov/pub/ameriflux/data/Level4/Sites_ByName/ Howland_Forest_Main/, Carbon Dioxide Inf. Anal. Cent., Oak Ridge Natl. Lab., Oak Ridge, Tenn.

Jackson, R. B., J. Canadell, J. R. Ehleringer, H. A. Mooney, O. E. Sala, and E. D. Schulze (1996), A global analysis of root distributions for terrestrial biomes, Oecologia, 108(3), 389-411.

Jolly, W., R. Nemani, and S. Running (2005), A generalized bioclimatic index to predict foliar phenology in response to climate, Global Change Biol., 11(4), 619-632.

Jothityangkoon, C., and M. Sivapalan (2009), Framework for exploration of climatic and landscape controls on catchment water balance, with emphasis on interannual variability, J. Hydrol., 371, 154-168, doi:10.1016/j.jhydrol.2009.03.030.

Klemeš, V. (1983), Conceptualization and scale in hydrology, J. Hydrol., $65,1-23$.

Lai, C., G. Katul, R. Oren, D. Ellsworth, and K. Schafer (2000), Modeling $\mathrm{CO}_{2}$ and water vapor turbulent flux distributions within a forest canopy, J. Geophys. Res., 105(D21), 26,333-26,351.

Law, B., K. Davis, L. Mahrt, C. Thomas, and D. Vickers (2009), Metolius Intermediate Pine FLUXNET Site L3 and L4 Data, ftp://cdiac.ornl.gov/ pub/ameriflux/data/Level4/Sites_ByName/Metolius_Intermediate_Pine/, Carbon Dioxide Inf. Anal. Cent., Oak Ridge Natl. Lab., Oak Ridge, Tenn.

Linacre, E. (1993), A 3-resistance model of crop and forest evaporation, Theor. Appl. Climatol., 48(1), 41-48.
Mahecha, M., et al. (2010), Comparing observations and process-based simulations of biosphere-atmosphere exchanges on multiple timescales, J. Geophys. Res., 115, G02003, doi:10.1029/2009JG001016.

Martin, T., R. Bracho, M. Castro, W. Cropper, and H. Gholz (2009a), Austin Cary FLUXNET L3 and L4 Data, ftp://cdiac.ornl.gov/pub/ameriflux/data/ Level4/Sites_ByName/Austin_Cary/, Carbon Dioxide Inf. Anal. Cent., Oak Ridge Natl. Lab., Oak Ridge, Tenn.

Martin, T., R. Bracho, and H. Gholz (2009b), Donaldson FLUXNET L3 and L4 Data, ftp://cdiac.ornl.gov/pub/ameriflux/data/Leve14/Sites ByName/Donaldson/, Carbon Dioxide Inf. Anal. Cent., Oak Ridge Natl. Lab., Oak Ridge, Tenn.

McDonnell, J. J., and R. Woods (2004), On the need for catchment classification, J. Hydrol., 299(1-2), 2-3.

Mellander, P., K. Bishop, and T. Lundmark (2004), The influence of soil temperature on transpiration: A plot scale manipulation in a young Scots pine stand, For. Ecol. Manage., 195(1-2), 15-28.

Meyers, T. (2009a), Audubon Research Ranch FLUXNET L3 and L4 Data, ftp://cdiac.ornl.gov/pub/ameriflux/data/Level4/Sites_ByName/Audubon Grasslands/, Carbon Dioxide Inf. Anal. Cent., Oak Ridge Natl. Lab., Oak Ridge, Tenn.

Meyers, T. (2009b), Fort Peck FLUXNET L3 and L4 Data, ftp://cdiac.ornl. gov/pub/ameriflux/data/Level4/Sites_ByName/Fort_Peck/, Carbon Dioxide Inf. Anal. Cent., Oak Ridge Natl. Lab., Oak Ridge, Tenn.

Meyers, T. (2009c), Goodwin Creek FLUXNET L3 and L4 Data, ftp:// cdiac.ornl.gov/pub/ameriflux/data/Level4/Sites_ByName/Goodwin Creek/, Carbon Dioxide Inf. Anal. Cent., Oak Ridge Natl. Lab., Oak̄ Ridge, Tenn.

Miller, G., D. Baldocchi, B. Law, and T. Meyers (2007), An analysis of soil moisture dynamics using multi-year data from a network of micrometeorological observation stations, Adv. Water Resour., 30(5), 1065-1081, doi:10.1016/j.advwatres.2006.10.0002.

Miller, G. R., X. Chen, Y. Rubin, S. Ma, and D. D. Baldocchi (2010), Groundwater uptake by woody vegetation in a semiarid oak savanna, Water Resour. Res., 46, W10503, doi:10.1029/2009WR008902.

Munger, J., S. Wofsy, E. Davidson, D. Fitzjarrald, and R. Varner (2009), Harvard Forest FLUXNET L3 and L4 Data, ftp://cdiac.ornl.gov/pub/ ameriflux/data/Level4/Sites_ByName/Harvard_Forest/, Carbon Dioxide Inf. Anal. Cent., Oak Ridge Natl. Lab., Oak Ridge, Tenn.

Nakai, T., et al. (2008), Parameterization of aerodynamic roughness over boreal, cool- and warm-temperate forests, Agric. For. Meteorol., 148(12), 1916-1925.

National Operational Hydrological Remote Sensing Center (2011), Snow Data Assimilation System (SNODAS) Data Products at NSIDC, http:// nsidc.org/data/g02158.html, Natl. Snow and Ice Data Cent., Boulder, Colo.

Neitsch, S., J. Arnold, J. Kiniry, and J. Williams (2005), SWAT theoretical documentation, version 2005, Soil and Water Assessment Tool, 494 pp., Tex. A\&M Univ., Temple.

Nemani, R., L. Pierce, S. Running, and L. Band (1993), Forest ecosystem processes at the watershed scale-Sensitivity to remotely sensed leaf area index estimates, Int. J. Remote Sens., 14(13), 2519-2534.

Oechel, W. (2009), Sky Oaks FLUXNET L3 and L4 Data, ftp://cdiac.ornl. gov/pub/ameriflux/data/Level4/Sites_ByName/Sky_Oaks_Old/, Carbon Dioxide Inf. Anal. Cent., Oak Ridge Natl. Lab., Oak Ridge, Tenn.

Oliphant, A., C. Grimmond, H. Zutter, H. Schmid, H. Su, S. Scott, B. Offerle, J. Randolph, and J. Ehman (2004), Heat storage and energy balance fluxes for a temperate deciduous forest, Agric. For. Meteorol., 126(3-4), $185-201$.

Powell, T., G. Starr, K. Clark, T. Martin, and H. Gholz (2005), Ecosystem and understory water and energy exchange for a mature, naturally regenerated pine flatwoods forest in north Florida, Can. J. For., 35(7), 1568-1580.

Raupach, M. R., and A. S. Thom (1981), Turbulence in and above plant canopies, Annu. Rev. Fluid Mech., 13, 97-129.

Raupach, M. R., J. J. Finnigan, and Y. Brunet (1996), Coherent eddies and turbulence in vegetation canopies: The mixing-layer analogy, Boundary Layer Meteorol., 78(3-4), 351-382.

Rutter, A. J., P. C. Robins, A. J. Morton, and K. A. Kershaw (1972), Predictive model of rainfall interception in forests. 1. Derivation of model from observations in a plantation of Corsican Pine, Agric. Meteorol., 9(5-6), 367.

Rutter, A. J., A. J. Morton, and P. C. Robins (1975), Predictive model of rainfall interception in forests. 2. Generalization of model and comparison with observations in some coniferous and hardwood stands, J. Appl. Ecol., 12(1), 367-380.

Sawicz, K., T. Wagener, M. Sivapalan, P. Troch, and G. Carrillo (2010), Catchment classification: Empirical analysis of hydrologic similarity based on catchment function, Hydrol. Earth Syst. Sci. Discuss., 8, 4495-4534. 
Saxton, K., and W. Rawls (2006), Soil water characteristic estimates by texture and organic matter for hydrologic solutions, Soil Sci. Soc. Am. $J ., 70(5), 1569-1578$.

Schenk, H. J., and R. B. Jackson (2002), The global biogeography of roots, Ecol. Monogr., 72(3), 311-328.

Schmalzer, P., and G. Hinkle (1990), Geology, geohydrology and soils of Kennedy Space Center: A review, NASA Tech. Memo., TM-103813.

Schwalm, C., et al. (2010), A model-data intercomparison of $\mathrm{CO}_{2}$ exchange across North America: Results from the North American Carbon Program site synthesis, J. Geophys. Res., 115, G00H05, doi:10.1029/ 2009JG001229.

Scott, R. (2009), Kendall FLUXNET L3 and L4 Data, ftp://cdiac.ornl.gov/ pub/ameriflux/data/Level4/Sites_ByName/Kendall_Grassland/, Carbon Dioxide Inf. Anal. Cent., Oak Ridge Natl. Lab., Oak Ridge, Tenn.

Scott, R., E. Hamerlynck, G. Jenerette, M. Moran, and G. Barron-Gafford (2010), Carbon dioxide exchanges in a semidesert grassland through drought-induced vegetation change, J. Geophys. Res., 115, G03026, doi:10.1029/2010JG001348.

Siqueira, M., G. Katul, D. Sampson, P. Stoy, J.-Y. Juang, H. McCarthy, and R. Oren (2006), Multiscale model intercomparisons of $\mathrm{CO}_{2}$ and $\mathrm{H}_{2} \mathrm{O}$ exchange rates in a maturing southeastern US pine forest, Global Change Biol., 12, 1189-1207, doi:10.111/j.1365-2486.2006.01,158.x.

Sitch, S., et al. (2003), Evaluation of ecosystem dynamics, plant geography and terrestrial carbon cycling in the LPJ dynamic global vegetation model, Global Change Biol., 9, 161-185.

Sivapalan, M., G. Bloschl, L. Zhang, and R. Vertessy (2003), Downward approach to hydrological prediction, Hydrol. Processes, 17, 2101-2111.

Stöckli, R., and P. L. Vidale (2005), Modeling diurnal to seasonal water and heat exchanges at European FLUXNET sites, Theor. Appl. Climatol, 80(2-4), 229-243.

Stöckli, R., D. Lawrence, G.-Y. Niu, K. Oleson, P. Thornton, Z.-L. Yang, G. Bonan, A. Denning, and S. Running (2008), Use of FLUXNET in the Community Land Model development, J. Geophys. Res., 113, G01025, doi:10.1029/2007JG000562.

Stoy, P., G. Katul, J.-Y. Juang, H. McCarthy, A. Oishi, J. Uebelherr, H.-S. Kim, and R. Oren (2006), Separating the effects of climate and vegetation on evapotranspiration along a successional chronosequence in the southeastern U.S., Global Change Biol., 12, 2115-2135.

Struthers, I., C. Hinz, and M. Sivapalan (2006), A multiple wetting front gravitational infiltration and redistribution model for water balance applications, Water Resour. Res., 42, W06406, doi:10.1029/2005WR004645.

Thomas, C., B. Law, J. Irvine, J. Martin, J. Pettijohn, and K. Davis (2009), Seasonal hydrology explains interannual and seasonal variation in carbon and water exchange in a semiarid mature ponderosa pine forest in central Oregon, J. Geophys. Res., 114, G04006, doi:10.1029/ 2009JG001010.

Thompson, S., C. Harman, P. Heine, and G. Katul (2010), Vegetationinfiltration relationships across climatic and soil type gradients, J. Geophys. Res., 115, G02023, doi:10.1029/2009JG001134.
Troch, P., G. Martinez, V. Pauwels, M. Durcik, M. Sivapalan, C. Harman, P. Brooks, H. Gupta, and T. Huxman (2009), Climate and vegetation water use efficiency at catchment scales, Hydrol. Processes, 23, 2409-2414, doi:10.1002/hyp. 7358 .

Wallace, J. S. (1995), Calculating evaporation-Resistance to factors, Agric. For. Meteorol., 73(3-4), 353-366.

Wang, X., A. M. Melesse, and W. Yang (2006), Influences of potential evapotranspiration estimation methods on SWAT's hydrologic simulation in a northwestern Minnesota watershed, Trans. ASABE, 49(6), 1755-1771.

Wang, Y., et al. (2004), Evaluation of the MODIS LAI algorithm at a coniferous forest site in Finland, Remote Sens. Environ., 91(1), 114-127.

Waring, R., B. Law, S. Bassow, R. McCreight, S. Wofsy, and F. Bazzaz (1995), Scaling gross ecosystem production at Harvard Forest with remote-sensing - A comparison of estimates from a constrained quantum-use efficiency model and eddy-correlation, Plant Cell Environ., 18(10), 1201-1213.

Whalley, W. R., B. Riseley, P. B. Leeds-Harrison, N. R. A. Bird, P. K. Leech, and W. P. Adderley (2005), Structural differences between bulk and rhizosphere soil, Eur. J. Soil Sci., 56(3), 353-360.

White, M., P. E. Thornton, S. W. Running, and R. R. Nemani (2000), Parameterization and sensitivity analysis of the BIOME-BGC terrestrial ecosystem model: Net primary production controls, Earth Interact., 4(3), pap. 3, doi:10.1175/1087-3562(2000)004<0003:PASAOT>2.0.CO;2.

Yang, S. D., and M. T. Tyree (1993), Hydraulic resistance in Acer saccharum shoots and its influence on leaf water potential and transpiration, Tree Physiol., 12(3), 231-242.

Yang, S. D., and M. T. Tyree (1994), Hydraulic architecture of Acer saccharum and A. rubrum - Comparison of branches to whole trees and the contribution of leaves to hydraulic resistance, J. Exp. Bot., 45(271), 179-186.

Yu, Z., and F. Schwartz (1998), Application of an integrated basin-scale hydrologic model to simulated surface-water and ground-water, Hydrol. Processes, 34(2), 409-425.

Yu, Z., W. Gburek, and F. Schwartz (2000), Evaluating the spatial distribution of water balance in a small watershed, Pennsylvania, Hydrol. Processes, 14(5), 941-956.

C. J. Harman and M. Sivapalan, Department of Civil and Environmental Engineering, University of Illinois at Urbana-Champaign, Urbana, IL 61801, USA. (charman2@illinois.edu; sivapala@illinois.edu)

A. G. Konings and S. E. Thompson, Nicholas School of the Environment, Duke University, Durham, NC 27707, USA. (agk5@duke.edu; set8@duke. edu)

A. Neal and P. A. Troch, Department of Hydrology and Water Resources, University of Arizona, Tuscon, AZ 85721, USA. (aneal@ email.arizona.edu; patroch@email.arizona.edu) 